\title{
The Role of Advanced Magnetic Resonance Imaging Techniques in Multiple Sclerosis Clinical Trials
}

\author{
Kedar R. Mahajan ${ }^{1} \cdot$ Daniel Ontaneda $^{1}$
}

Published online: 2 August 2017

(C) The American Society for Experimental NeuroTherapeutics, Inc. 2017

\begin{abstract}
Magnetic resonance imaging has been crucial in the development of anti-inflammatory disease-modifying treatments. The current landscape of multiple sclerosis clinical trials is currently expanding to include testing not only of anti-inflammatory agents, but also neuroprotective, remyelinating, neuromodulating, and restorative therapies. This is especially true of therapies targeting progressive forms of the disease where neurodegeneration is a prominent feature. Imaging techniques of the brain and spinal cord have rapidly evolved in the last decade to permit in vivo characterization of tissue microstructural changes, connectivity, metabolic changes, neuronal loss, glial activity, and demyelination. Advanced magnetic resonance imaging techniques hold significant promise for accelerating the development of different treatment modalities targeting a variety of pathways in MS.
\end{abstract}

Keywords Advanced imaging · Clinical trials · Multiple sclerosis $\cdot$ Magnetic resonance imaging $\cdot$ MRI

\section{Conventional Imaging}

In clinical trials, conventional magnetic resonance imaging (MRI) has been used to confirm the diagnosis and determine efficacy of disease-modifying treatments (DMTs) through

Electronic supplementary material The online version of this article (doi:10.1007/s13311-017-0561-8) contains supplementary material, which is available to authorized users.

Daniel Ontaneda

ontaned@ccf.org

1 Mellen Center for Multiple Sclerosis Treatment and Research, Cleveland Clinic, 9500 Euclid Avenue, U-10, Cleveland, OH 44195 , USA measurement of new lesion counts and volumes. A very strong correlation between the effect on new lesion formation and the effect on relapses has been found with DMTs and allowed for screening of novel therapeutics in phase II trials [1]. The term "no evidence of disease activity", referring to a composite of a lack of 1) clinical relapses; 2) Expanded Disability Status Scale (EDSS) progression; and 3) MRI activity [new/enlarging T2 or gadolinium-enhancing (GdE) lesions and possibly brain atrophy] was based on outcomes routinely collected in contemporary clinical trials, but may be applied in clinical practice [2]. Furthermore, the presence of T1 hypointensities ("black holes"), has been characterized as the hypointensities indicate more significant axonal loss [3] and correlate with increased disability [4]. More diffuse measures of tissue injury, including measurement of whole-brain or gray-matter volumes, have been used extensively in clinical trials as secondary outcomes. There are ongoing improvements in acquisition methods [5], increased field strengths for superior signal or contrast to noise ratio [6], and contrast agents [7] to improve lesion identification.

There are noteworthy limitations with conventional imaging that contribute to the so-called clinicoradiological paradox. "Normal-appearing" white and gray matter (NAWM and NAGM, respectively) by conventional standards retain significant abnormalities detectable only by more advanced techniques. Even the canon that white matter (WM) T2/fluidattenuation inversion recovery (FLAIR) lesions depict demyelination has been challenged with findings of normal myelin content in up to $30 \%$ of $\mathrm{T} 2$ hyperintense/T1 hypointense/low magnetization transfer ratio (T2/T1/MTR) lesions [8]. Developments in imaging methodology with histopathologic and clinical correlations will greatly improve our ability to test specific pathogenic mechanisms and therapeutic targets.

Whole-brain atrophy (WBA) in multiple sclerosis (MS) occurs at a rate approximately 3 times faster than healthy 
controls [9] early in the course [10], can limit brain grown in pediatric-onset MS [11], correlates with disability progression [12], and is associated with cerebrospinal fluid (CSF) levels of neurofilament light chain and tau [13]. Evaluating brain volume as a secondary outcome in trials is feasible and has demonstrated effects for nearly all approved MS DMTs and has been used as a primary outcome in secondary progressive MS [14]. WBA, however, has been criticized as it changes slowly, and there is considerable variability within subjects and across different atrophy software algorithms.

\section{Advanced Imaging}

Techniques discussed here strive to provide greater in vivo insight into the neurodegenerative and inflammatory aspects of MS otherwise unrecognized using conventional imaging. These methods may provide improved sensitivity as biomarkers of disease activity and progression, and may even be used as surrogate outcome measures of efficacy in therapeutic clinical trials.

\section{Cortical Lesions}

Lesion detection is paramount for monitoring disease activity and efficacy of DMTs [15, 16]. Cortical lesions (CLs), more common in secondary progressive MS (SPMS) than in clinically isolated syndrome (CIS) or relapsing remitting MS (RRMS) [17], are nearly invisible by conventional techniques but can be more readily identified using advanced methods. Cortical and deep gray matter (GM) pathology surpasses WM lesions in association with disability, progression [18], and cognitive impairment $[19,20]$. Use of ultra-high field 7 Tesla (T) MRI nearly doubles CL detection versus $3 \mathrm{~T}$ and is able to detect $100 \%$ leukocortical, $11 \%$ intracortical, $32 \%$ subpial, and $68 \%$ subpial extending entire width of the cortex (types 1-4, respectively), with postmortem validation [21]. Three-dimensional (3D) double inversion recovery (DIR) allows for suppression of the CSF and WM in FLAIR, detects $18 \%$ of CLs versus postmortem verification, and is 1.6-fold superior to 3D-FLAIR [22]. Phase-sensitive inversion recovery may be useful concomitantly with DIR to further improve CL contrast [23]. GM juxtacortical lesions have been identified with phase difference-enhanced imaging [24], and 3D magnetization-prepared rapid acquisition with gradient echo can also help classify CL type [25].

CL volume may be an additional outcome measure to WM lesion burden in clinical trials given its potential for correlating with EDSS. Trials that employ neuroprotective measures or target cognition may specifically benefit from CL measurement. Furthermore, distinguishing specific CL types, such as leukocortical lesions, may improve correlations with cognitive impairment [26].

\section{Regional Atrophy}

Regional measures in atrophy may provide improved specificity for different pathogenic processes in MS and may be used as candidate measures for clinical trials. Regional and deep GM atrophy is noted early in MS and correlates with disability progression more than WBA or T2 lesion volume (T2LV) [27]. Evaluating GM fraction independently has unmasked its potential for predicting disability and risk of secondary progression [28]. Thalamic atrophy, in particular, is present even in CIS [29]; is associated with the risk of clinically definite MS; and can be useful in discriminating MS from neuromyelitis optic spectrum disorders (NMOSD) [30]. Thalamic volume is overwhelmingly associated with cognitive impairment in MS [31], and is a reflection of extrathalamic injury more significantly than thalamic lesions [32].

\section{Diffusion Tensor Imaging}

Diffusion tensor imaging (DTI) is an imaging technique that reflects microstructual changes in tissue by investigating the Gaussian diffusivity of water. Each voxel represents a measurement of multiple diffusion-weighted acquisitions that is modeled mathematically as a diffusion tensor - a $3 \times 3$ matrix comprised of 3 perpendicular eigenvectors with corresponding eigenvalues. Diffusion in WM is anisotropic (not equally restricted in all directions) and follows the direction of the axon. DTI measures include fractional anisotropy (FA), mean diffusivity (MD), axial diffusivity (AD) (sometimes referred to as longitudinal diffusivity), and radial diffusivity (RD) (sometimes referred to as transverse diffusivity).

$\mathrm{RD}$ is calculated as the mean of the 2 eigenvectors perpendicular to the long axis of the diffusion ellipsoid and inversely correlates with myelin content [33]. AD is the eigenvector parallel to the direction of the ellipsoid and has been loosely correlated with axonal content [34]. MD is calculated as the mean of all 3 eigenvectors and increases with architectural injury from increased isotropic water diffusion [35]. FA is an index of the asymmetry or directional preference of diffusion in a voxel and correlates with axonal counts and myelin content in MS [36]. While the degree of decrease in FA correlates to decreased axons and myelin [37], an increase in GM (cortex and thalamus) is thought to be due to decreased dendritic arborization [38]. These metrics are able to identify subtle changes in prelesional NAWM and NAGM, and lesional tissue that is otherwise unapparent or indistinguishable by conventional imaging.

In acute MS lesions, a reproducible pattern of decreased FA, increased MD, and increased RD is generally seen. Changes in NAWM, such as decreased FA and increased $\mathrm{MD}$ and $\mathrm{RD}$, can be detected at baseline in CIS and progress over time. [39]. Comparing progressive courses, the average lesional, NAWM, and NAGM MD is higher in SPMS versus 
primary progressive MS (PPMS) [40]. DTI is also able to detect changes in normal-appearing cortical and deep GM. MD increases in NAGM of untreated patients with RRMS over time independent of brain atrophy [41]. DTI measurements in the thalamus also change in patients with MS versus controls [42]. Increases in thalamic MD are relevant as they correlate with global EDSS, as well as T1 and T2LV [43]. While reduction in thalamic FA correlates with thalamic atrophy, thalamic or WM lesions do not [44].

DTI changes are apparent in even in prelesional NAWM. Increase in NAWM MD, suggestive of tissue injury, precedes GdE by 6 weeks [45]. RD and MD increases also have been noted 10 months prior to $\mathrm{GdE}$, suggesting tissue injury prior to breakdown of the blood-brain barrier [46].

DTI has the potential to discriminate evolution of lesions, as well as mechanistic differences. FA has been shown to decrease in major WM tracts following GdE, even in locations distinct from the lesion location when tracked longitudinally [47]. The majority of chronic T2 lesions have a T1 hypointensity ("black hole") at their core characterized by axonal loss [3] with higher AD and RD [48]. Active lesions with increased $\mathrm{RD}$ in 1 study suggested more severe demyelination and predicted the development of $\mathrm{T} 1$ hypointensities [49]. Another study found increased AD in active lesions, and the authors speculated glial recruitment may have been responsible [50]. Interestingly, the T2 rim in the periphery of a lesion has significantly higher RD compared with $\mathrm{AD}$, suggesting relative axonal preservation [48].

Other methods to characterize myelin injury or clinical disability corroborate DTI measurements. Changes in DTI metrics along WM tracts correlate with quantitative $\mathrm{T} 2 *$, a marker of iron deposition due to myelin injury, in associated and unrelated cortical projections. Associations between DTI metrics (e.g., $\mathrm{AD}$ and $\mathrm{RD}$ ) also correlate with clinical measures such as the pyramidal EDSS subscore and Symbol Digit Modalities Test (SDMT) [51].

DTI has been used to identify the association between specific cognitive domain impairment and functional networks. FA was found to be decreased in the limbic pathway, particularly the cingulum, fornix, and uncinate WM tracts, in relapsing MS versus control [52]. Decreased FA and increased RD correlated with SDMT measures in tracts associated with cognition [53]. A decrease in hippocampal FA was present in patients with CIS more than controls and an increased hippocampal MD was able to discriminate patients with CIS and poor delayed recall [54].

DTI has been used to evaluate therapeutic effects in small studies and clinical trials. A study evaluating walking performance with patients with MS found correlations between MD, $\mathrm{AD}$, and RD with clinical outcomes [55]. A longitudinal study of patients with MS who underwent balance training with a video game balance board (Nintendo Wii ${ }^{\circledR}$ ), had transiently increased FA and RD in the superior cerebellar peduncles paralleling clinical balance improvement with static posturography after 12 weeks [56].

There have been some promising findings in pilot studies using DTI to investigate DMTs. A longitudinal study of 23 patients with various MS courses on dalfampridine for 2 weeks found 12 clinical responders who were also noted to have reductions of MD and RD involving the corticospinal tract and optic radiations among other tracts. [57]. The authors speculated the changes were due to a sensitive pool of potassium channels that changed the osmotic balance along the axon upon closure. A short observational study of 4 patients followed on fingolimod for 4 months with DTI noted widespread increase in MD in NAWM and FLAIR lesions without any clinical manifestations [58]. A 1-year longitudinal study noted the differential effect on FA when comparing natalizumab, interferon (IFN)- $\beta$, and glatiramer acetate [59] These findings supported decreased severity of damage with natalizumab, which correlated with cognitive performance [59]. In an open-label phase IIA study of patients with progressive MS with oral methylprednisolone $1.5 \mathrm{~g}$ monthly, decreases in MD in NAWM and NAGM were found after 15 months [60]. The SPRINT-MS trial will be using DTI as an outcome measure for neuroprotection in a study of ibudilast in progressive MS [61].

Some limitations exist with DTI measures. The complexity of MS pathology, including infiltrating cells and crossing fibers, may interfere with DTI measurements. Equating AD with axonal integrity may be an oversimplification of a complex process. Increased RD appears to be a sensitive measure of active lesions, but its utility in NAWM is less clear. Efforts have been made to overcome some of these limitations. The development of diffusion basis spectrum imaging, a novel computational method to separate cellular edema (isotropic) from axonal/myelin integrity (anisotropic), can potentially be applied to progressive MS to follow neurodegeneration more effectively [62]. Other advanced diffusion modeling methods, such as neurite orientation dispersion and density imaging, improve on DTI parameters to provide greater microstructual specificity [63].

Despite these limitations, DTI can be a valuable metric to evaluate microstructual changes in tissue and integrity of tracts. These metrics could particularly serve as useful outcome measures in clinical trials seeking to evaluate the extent of neurodegeneration and evaluate the efficacy of neuroprotective strategies.

\section{Functional MRI and Connectivity}

Functional MRI (fMRI) exploits the diamagnetic and paramagnetic properties of oxyhemoglobin and deoxyhemoglobin, respectively, as a noninvasive blood oxygen level-dependent endogenous contrast in a gradient-echo (GRE) sequence [64]. The oxy/deoxyhemoglobin ratio in GM 
provides insight into activated areas in resting-state (rs-fMRI), default mode network, and task-related recruitment fMRI. These techniques provide a window into correlating clinical metrics with reorganization, plasticity, and functional reserve in MS phenotypes.

fMRI is a unique MRI modality as it allows detection of functional changes in addition to anatomical and pathological changes. Several early studies support the hypothesis that subjects with MS have an increase in activation and functional connectivity in several brain regions as a likely adaptive mechanism [65]. In multiple regions in CIS, rs-fMRI synchronization increases initially but later declines in advanced stages of MS, suggesting early adaptive increased connectivity with subsequent reduced reorganization later in the course owing to tissue injury [66]. Another method used to study rs-fMRI in CIS found an initial decrease in activity in several brain regions [67]. The precise timing and biology of these compensatory changes is unclear. In radiologically isolated syndrome (RIS), no differences between rs-fMRI and healthy controls are found, despite the presence of brain and spinal cord lesions, CSF oligoclonal bands, dissemination in time, and atrophy [68]. During the more manifest stages of RRMS most studies have shown increased connectivity and activation. In the later stages of disease, it appears that connectivity tends to decrease and these changes are associated with cognitive manifestations [69]. Functional connectivity decreases with disease progression [70] and disruption in thalamocortical connectivity occurs independently of T2LV and thalamic volume [71].

Compared with healthy controls, task-related activation fMRI in CIS exhibits increased recruitment in cortical and thalamic regions [72]. Task-related fMRI can discriminate between CIS, relapsing MS without disability or with mild disability, and SPMS [69]. Increased recruitment may also explain favorable clinical outcomes, as a more "benign" phenotype [73]. Patients with PPMS have increased nonmotor activation, suggesting an adaptive response [74]. Hyperactivation is also noted in the cervical cord in PPMS following tactile stimulation and correlates with disability [75].

Cognitive impairment has been evaluated along with several fMRI methods. The Paced Auditory Serial Addition Task (PASAT), a component of the MS Functional Composite, is a validated tool to screen for cognitive impairment in MS and correlates with rs-fMRI functional connectivity and taskrelated activation differences in MS [76]. Other neuropsychological assessments evaluating processing speed and executive function correlate with rs-fMRI [77] and activation [78] in cortical and deep GM regions. Task-related activation is able to identify patients with working memory impairment [79]. Default mode network, a state that is active at rest and deactivated with goal-directed tasks, is aberrant in cognitive impairment in MS [80]. Changes in functional connectivity patterns are also present in MS using MRI with resting-state magnetoencephalography [81].
Fatigue is prevalent in MS and is associated with unique hyperactivation of certain motor-attention networks during the performance of a simple task [82]. Cognitive fatigue, or impaired ability to sustain mental effort, is associated with cortical and subcortical hyperconnectivity following PASAT administration using rs-fMRI [83] and with a modified SDMT during taskactivated fMRI [84].

Early recognition of functional connectivity changes in MS with fMRI provides a window for intervention before significant cognitive impairment takes hold and adaptations are no longer adequate. Many multicenter studies have been performed by the MRI in MS group, demonstrating their feasibility [85]. A few small trials have investigated connectivity changes with task-related fMRI for cognitive rehabilitation with transcranial magnetic stimulation [86], with rs-fMRI for Nintendo ${ }^{\circledR}$ [87], and memory retraining (modified Story Memory Technique) [88]. Given these findings and small studies suggesting the between-scanner and between-subject reproducibility of rs-fMRI [89, 90] and task-related fMRI [91] measures, there exists a significant potential for their use as key secondary outcomes in cognitive rehabilitation trials.

\section{Magnetization Transfer}

Magnetization transfer (MT) is a method to observe exchange between unbound protons in a free water pool with protons bound to macromolecules (myelin and cells) [92]. A MT radio-frequency pulse transfers energy to the bound pool and then to the unbound pool by dipole interactions. The MTR is the difference in the signal before and after the MT pulse divided by the signal before the pulse. Histopathologic studies have confirmed MTR correlates with myelin content and axonal density [93]. MTR can also distinguish remyelinated lesions from NAWM and demyelinated lesions [94].

MTR decreases 3 to 18 months prior to the appearance of a new T2 or GdE lesion [95], possibly as a result of edema, perivascular inflammation, demyelination, or activation of astrocytes/microglia, and predicts the likelihood of recovery. In patients with CIS, MTR is noted to be decreased in NAWM and NAGM [96]; the decrease is less prominent than in relapsing MS but can predict progression to clinically definite MS [97], and correlates with future disability [98]. MTR decreases in NAWM in MS correlate with disease duration [99] and also predicts disability [100]. MTR decreases in GM occur early and are associated with disability and cognitive impairment in MS. With ultra-high-field MRI, CLs have been detected using MTR [101]. Global [102] and cortical [103] MTR decreases correlate with cognitive impairment even more than T2LV.

MTR has been proposed as a measure of remyelination for therapeutic trials. MTR exhibits temporal changes with decrease in prelesional tissue and GdE lesions and recovery to 
baseline in subsequent months [104]. Improvement in MTR was observed with IFN- $\beta 1 \alpha$ in RRMS [105] but not SPMS [106]. Increase in MTR in acute and chronic black holes with glatiramer acetate are also observed [107]. Variable results are noted in trials involving dimethyl fumarate, either reaching [108] or not reaching [109] statistical significance for increase in MTR. Natalizumab shows increases in both NAWM and cortical GM [110] and more robustly so than IFN- $\beta 1 \alpha[111]$. Alemtuzumab treatments have been shown to stabilize MTR in NAGM [112]. Ongoing phase II clinical trials have also used MTR to evaluate for possible recovery or neuroprotective effects, including GSK239512, a histamine H3 receptor antagonist [113], and ibudilast in progressive MS (SPRINTMS) [61]. These findings are promising for its use in future clinical trials striving to detect improvement of microstructual injury with protective strategies.

\section{Proton magnetic resonance spectroscopy}

Magnetic resonance spectroscopy (MRS) provides 3D quantitative information based on the properties of different nuclei (e.g., ${ }^{1} \mathrm{H},{ }^{31} \mathrm{P},{ }^{13} \mathrm{C},{ }^{23} \mathrm{Na}$ ) and their respective relaxation times. Proton $\left({ }^{1} \mathrm{H}\right)$ MRS, in particular, has been utilized for characterizing MS pathology since the early 1990s and can typically be acquired in $<20 \mathrm{~min}$ [114]. Using characteristic ${ }^{1} \mathrm{H}$ shifts, metabolites can be identified with a resonance signal intensity proportional to its relative concentration. Novel methods overlying spectrographic maps on anatomic sequences ( $\mathrm{T} 1$ and FLAIR) have also improved resolution [115] and allowed for global and local measurements [116]. Tracking metabolic changes in lesional and normal-appearing tissue allows indirect detection of neuronal, axonal, and glial differences.

Pathologic confirmations of MRS changes in human demyelinating lesions demonstrate significant correlations between $\mathrm{N}$-acetylaspartate (NAA) and decreases in myelin and axonal density. Increases in choline (Cho) and myo-inositol (mIns) are associated with glial proliferation [117]. Animal models, including a longitudinal model of demyelination using cuprizone, have also detected decreases in NAA and glutamate with demyelination and a return to normal following near-complete remyelination [118].

NAA is synthesized in neuronal mitochondria and has been extensively used as a surrogate for neuronal/axonal loss and correlates with disability [119]. Correlations have been found also in those with moderate disability (EDSS < 5) [120], shorter disease duration [120], and in the cortex [121]. Although whole-brain NAA does not correlate with disability or lesion load [122], reductions of NAA in patients with mild symptoms suggests their lack of significant disability may be due to fortuitous avoidance of eloquent cortex or compensatory changes from plasticity. Decrease in NAWM NAA appears to occur independently to changes in NAGM [123]. Changes in NAA and other metabolites have been useful to discriminate from healthy controls [124] or patients with NMOSD [125]. Parallel reduction of NAA with retinal nerve fiber layer thinning over 1 year without EDSS changes [126] further validates its utility for detecting subtle changes.

Other metabolites such as creatinine, Cho, mIns, $\gamma$ aminobutyric acid, glutamate/glutamine, and glutathione have been used to study non-neuronal changes, such as gliosis, demyelination, inflammation in particular disease courses, spatial tracts, degrees of disability, and symptoms such as pain [127]. Table 1 summarizes metabolite patterns and their hypothesized significance in lesional and normal-appearing tissue.

${ }^{1} \mathrm{H}-\mathrm{MRS}$ may be a useful outcome in MS clinical trials [137], and guidelines have been proposed for its use [138]. MRS has been studied with IFN- $\beta$, glatiramer acetate, biotin, and natalizumab. With IFN- $\beta$, results have been mixed, with NAA shown to increase [139] or decrease [140] while on treatment,and with either an increase or no change in Cho [141, 142]. In a cross-sectional study, an increase in NAA was noted after 4 years of treatment with glatiramer acetate, which correlated with EDSS [143]. No differences in NAA and Cho were seen comparing glatiramer acetate with placebo in patients with a primary progressive course [144]. Despite treatment with natalizumab, increased creatinine and Cho (measures of membrane phospholipid turnover) correlating with increased levels with CSF inflammatory markers IL-1 $\beta$ and CXCL8 may indicate persistent gliosis and inflammation [145]. However, lesional levels of NAA, Cr, and phosphocreatine increase with natalizumab versus IFN- $\beta$ or glatiramer acetate, suggesting improved axonal metabolism [146]. Neuroprotective effects in pilot studies with high doses of biotin show some normalization of Cho in NAWM [147]. Similarly, an increase in NAA after 2 weeks of fluoxetine has been described [148].

Several challenges to the use of spectroscopy in MS remain. Changes in metabolite levels in MS are expressed as a ratio rather than an absolute measure. Use of an external standard (phantom) with a defined amount of metabolite can be used for quantification. Other limitations of MRS include partial volume effects with small lesions and inability to perform whole-brain acquisitions on clinical scanners. Although the technique is becoming more refined, low reproducibility of ${ }^{1} \mathrm{H}$-MRS across centers may present a challenge for implementation in a multicenter study [128].

\section{Sodium MRS}

Sodium $\left({ }^{23} \mathrm{Na}\right)$ MRS has been used in MS and is attractive as an outcome measure as it may reflect several underlying pathological pathways. Elevated sodium concentrations in tissue may reflect demyelinated axons that redistribute sodium $\left(\mathrm{Na}^{+}\right)$ channels from nodes of Ranvier to along the axon and $\mathrm{Na}^{+}$ channel upregulation in astrocytes and microglia/ 
Table 1 Characteristics of ${ }^{1} \mathrm{H}$-magnetic resonance spectroscopy metabolites in multiple sclerosis

\begin{tabular}{|c|c|c|c|c|c|c|}
\hline ppm & Metabolite & Pathologic correlate & $\begin{array}{l}\text { NAWM/ } \\
\text { prelesional }\end{array}$ & $\begin{array}{l}\text { CGM/ } \\
\text { NAGM }\end{array}$ & $\begin{array}{l}\text { Acute or GdE } \\
\text { lesion }\end{array}$ & Chronic lesion \\
\hline $0.9-1.4$ & Lipids & Tissue destruction & $\uparrow[128]$ & $\uparrow[128]$ & $\uparrow[128]$ & $-\downarrow[128]$ \\
\hline 1.33 & Lactate & $\begin{array}{l}\text { Anaerobic glycolysis Inflammatory } \\
\text { cell metabolism, neuronal } \\
\text { mitochondrial dysfunction, } \\
\text { ischemia }\end{array}$ & & & $\uparrow[129]$ & $-[128]$ \\
\hline 2.02 & $\mathrm{NAA}^{*}$ & Present in neuronal/axons & $\downarrow[130,131]$ & $\downarrow[128]$ & $\downarrow[132]$ & $\downarrow[133]$ \\
\hline $2.0-2.4$ & Glutamate, GABA & Neuroexcitotoxicity & $\uparrow[133]$ & $\downarrow[128]$ & $\uparrow$ & $-[133]$ \\
\hline$?$ & Glutathione & & $-[134]$ & $\downarrow[134]$ & & \\
\hline 3.03 & $\begin{array}{l}\text { Creatine, } \\
\text { phosphocreatine }\end{array}$ & $\begin{array}{l}\text { Energy metabolism in neurons and } \\
\text { glia }\end{array}$ & $\uparrow[135]$ & $\uparrow \downarrow[128]$ & $\downarrow$ & $\uparrow$ \\
\hline 3.22 & Choline compounds $*, \dagger$ & $\begin{array}{l}\text { De-/remyelination, inflammation } \\
\text { Release of membrane } \\
\text { phospholipids }\end{array}$ & $\uparrow[136]$ & $\downarrow[128]$ & $\uparrow[129]$ & $\downarrow[132], \uparrow[128]$ \\
\hline 3.56 & Myoinositol & Glial marker, osmolyte & $\uparrow[128]$ & $\uparrow \downarrow[128]$ & $\uparrow[129]$ & $\uparrow$ \\
\hline
\end{tabular}

$(-)=$ unchanged; $\uparrow=$ increased; $\downarrow=$ decreased; NAWM = normal-appearing white matter; CGM = cortical gray matter; NAGM = normal-appearing gray matter; GdE = gadolinium-enhancing; $\mathrm{NAA}=N$-acetylaspartate; GABA $=\gamma$-aminobutyric acid

*Typically normalized to creatine in voxel

${ }^{\dagger}$ Includes free choline, phosphorylcholine, glyceryl-phosphoryl-choline; possibly taurine and betaine

macrophages [149]. Additionally, mitochondrial dysfunction in MS likely limits compensatory mechanisms, such as the sodium/potassium pump and sodium/calcium exchanger in injured tissue [150], causing accumulation of intracellular sodium [149] and serving as a potential biomarker. Despite the 1/5000th signal intensity compared with ${ }^{1} \mathrm{H}-\mathrm{MRS}$ [151], causing poorer signal-to-noise ratio, advances have permitted ${ }^{23} \mathrm{Na}$-MRS to detect total (TSC), intracellular (ISC), and indirect extracellular sodium concentrations in tissue.

TSC is increased in the NAWM, NAGM, GdE lesions, and T1 hypointense lesions in RRMS versus healthy controls $[152,153]$. TSC increases in NAWM with disease duration and TSC levels in NAGM correlate with EDSS and T2LV [154]. In both SPMS and PPMS, TSC is increased in NAGM and T2 lesions versus healthy controls [155], and patients with SPMS have elevated TSC in NAWM, cortical GM, and deep GM versus those with RRMS [156]. TSC distribution is more restricted to motor regions in PPMS than in SPMS [155] and associated with disability in particular motor regions. Irrespective of the course, TSC in deep GM and T1 hypointense lesions correlate modestly with disability measures [156].

More recent adaptations can discriminate ISC from TSC. With fluid-attenuated ${ }^{23} \mathrm{Na}-\mathrm{MRS}$, ISC is increased in GdE lesions versus chronic lesions in RRMS, and levels decrease following intravenous methylprednisolone [157]. ISC is also elevated in cortical, subcortical, and NAWM in patients with RRMS versus healthy controls using triple-quantum-filtered ${ }^{23} \mathrm{Na}-\mathrm{MRS}$ at $7 \mathrm{~T}$ and indirect extracellular sodium concentration measures and TSC correlate with T2LV, T1LV, and EDSS [158].
${ }^{23} \mathrm{Na}-\mathrm{MRS}$ may prove useful in future clinical trials with therapeutics targeting neuroprotection and mitochondrial dysfunction. However, multicenter application of this technology may pose challenges and remains to be tested. Preclinical evidence in animal models of MS show promise and phenytoin has shown protective effects in the optic nerve [159], whereas lamotrigine did not seem to have an effect on atrophy measurements [160]. Oxcarbazepine is currently being investigated in a clinical trial incorporating TSC as an outcome (NCT02104661).

\section{Positron Emission Tomography}

Positron emission tomography (PET) has been used since the 1950s to localize brain tumors and has been used in MS since the 1990s. Specific isotope-labeled tracers have been developed that target receptors, $\beta$-amyloid, and metabolites. These targets putatively provide in vivo functional information about axonal degeneration, demyelination/remyelination, microglial activation, and astrogliosis. Differences have been observed in CIS, early MS, and between relapsing and progressive MS. Correlation of PET ligand uptake with other modalities such as T2LV, T1 black holes, atrophy, and disability measures will be reviewed below. PET ligands are also summarized in Table 2.

${ }^{11} \mathrm{C}$-Flumazenil binds to the benzodiazepine site of the $\gamma$ aminobutyric acid A receptor expressed on cortical and deep GM neurons and reduction in its uptake correlates with neuronal loss [186]. Correlation of its uptake with cognitive impairment [186] is consistent with the loss of hippocampal 
Table 2 Summary of positron emission tomography ligands used in clinical multiple sclerosis (MS) studies

\begin{tabular}{|c|c|}
\hline Isotope & Clinical study findings \\
\hline $\begin{array}{l}\text { TPSO } \\
\text { Microglial activation } \\
{ }^{11} \text { C-PK11195 } \\
\text { First-generation }\end{array}$ & 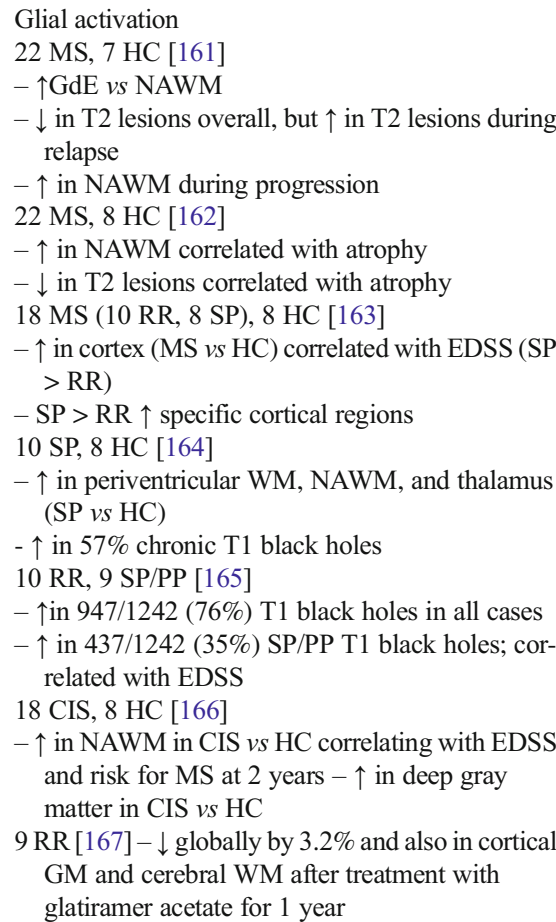 \\
\hline Second-generation & 1. 9 RR with GdE, 5 HC [168] \\
\hline $\begin{array}{l}\text { Higher affinity and } \\
\text { greater specificity } \\
1 .{ }^{18} \mathrm{~F}-\mathrm{FEDAA} 1106 \\
2 .{ }^{11} \mathrm{C} \text {-PBR28 } \\
\text { 3. }{ }^{11} \mathrm{C} \text {-vinpocetine } \\
\text { 4. }{ }^{18} \mathrm{~F}-\mathrm{DPA}-714 \\
5 .{ }^{18} \mathrm{~F}-\mathrm{PBR} 06 \\
6 .{ }^{11} \mathrm{C}-\mathrm{PK}-1195\end{array}$ & $\begin{array}{l}\text { - no difference } \\
\text { 2. } 11 \text { MS, } 7 \text { HC }[169] \\
-\uparrow \text { in GdE vs NAWM } \\
-\uparrow \text { in prelesional areas } \\
\text { - global levels correlated with disease duration } \\
\text { RR stable, } 1 \text { RR active [170] } \\
\text { - reproducible and } \uparrow \text { in GdE } \\
\text { 15 SP, } 12 \text { RR, } 14 \text { HC [171] } \\
-\uparrow \text { in cortex and cortical lesions (7T T2*) } \\
-\uparrow \text { SP > RR } \\
- \text { uptake in cortex, deep GM, and NAWM } \\
\text { correlated with disability and cognitive } \\
\text { impairment } \\
- \text { cortical thinning correlated with } \uparrow \text { in thalamus } \\
\text { 3. } 4 \text { MS [172] } \\
-{ }^{11} \text { C-vinpocetine parallels }{ }^{11} \mathrm{C}-\mathrm{PK} 11195 \text { but has } \\
\text { higher signal } \\
\text { 4. NCT02305264: ongoing trial recruiting patients } \\
\text { with relapsing and progressive MS } \\
\text { 5. NCT02649985: ongoing trial recruiting patients } \\
\text { with relapsing and SPMS in comparison with } \\
\text { HC and Alzheimer's disease } \\
\text { 6. NCT02207075: ongoing trial recruiting patients } \\
\text { with SPMS }\end{array}$ \\
\hline A2A adenosine receptor & 8 SPMS, 7 HC [173] \\
\hline $\begin{array}{l}\text { Upregulated in activated } \\
\text { microglia } \\
{ }^{11} \mathrm{C} \text {-TMSX }\end{array}$ & $-\uparrow$ NAWM and correlated with disability \\
\hline $\begin{array}{l}\text { Astrocyte marker } \\
{ }^{11} \mathrm{C} \text {-acetate }\end{array}$ & $\begin{array}{l}6 \text { RRMS, } 6 \text { HC }[174] \\
-\uparrow \mathrm{WM} \text { and GM in MS } \\
- \text { correlates with T2 lesions and T1 black holes }\end{array}$ \\
\hline $\begin{array}{l}\text { High affinity for CNS } \\
\text { myelin } \\
\text { Amyloid tracers } \\
\text { 1. }{ }^{11} \mathrm{C}-\mathrm{PiB}\end{array}$ & $\begin{array}{l}\text { 1. } 2 \text { MS }[175] \\
- \text { correlates with myelin } \\
20 \text { RR, } 8 \text { HC }[176] \\
-\downarrow \text { in MS lesions }\end{array}$ \\
\hline
\end{tabular}

Table 2 (continued)

\begin{tabular}{|c|c|}
\hline Isotope & Clinical study findings \\
\hline 2. ${ }^{18} \mathrm{~F}$-florbetaben & $\begin{array}{l}\text { - longitudinal variability suggested remyelination } \\
\text { and inversely correlated with disability } \\
\text { 2. } 12 \text { MS ( } 5 \text { RR, } 2 \text { SP, } 2 \text { PP), } 3 \text { HC [177] } \\
-\downarrow \text { in T2 lesions and correlated with EDSS } \\
-\downarrow \text { in progressive } v s \text { relapsing patients }\end{array}$ \\
\hline Glucose metabolism & $8 \mathrm{MS}, 8 \mathrm{HC}$ [178] \\
\hline${ }^{18} \mathrm{~F}-\mathrm{FDG}$ & $\begin{array}{l}-\downarrow \text { in thoracic and lumbar spinal cord after walking } \\
1 \text { MS }[179] \\
-\uparrow \text { in } 2 \text { T2 lesions in acute presentation of } \\
\text { tumefactive MS } \\
2 \text { MS [180] } \\
- \text { no uptake in lesions resembling tumefactive MS } \\
\text { or Balo's concentric MS } \\
17 \text { RR, } 18 \text { HC [181] } \\
-\downarrow \text { uptake in cortical and deep GM structures with } \\
\text { variable correlation to lesions } \\
10 \text { MS [182] } \\
-\downarrow \text { in cortex over } 2 \text { years } \\
23 \text { MS, } 9 \text { HC [183] } \\
-\downarrow \text { uptake in cortical and regional (dorsolateral } \\
\text { prefrontal, orbitofrontal, caudate, putamen, } \\
\text { thalamus, and hippocampus) } \\
-\downarrow \text { cortical correlated with T2LV } \\
-\uparrow \text { in right thalamus correlated with improved } \\
\text { cognitive performance } \\
16 \text { RR, } 12 \text { SP, } 10 \text { HC }[184] \\
-\downarrow \text { in thalamus and other deep grey matter } \\
\text { structures (e.g., hippocampus and cingulate } \\
\text { gyrus) } \\
47 \text { MS, } 16 \text { HC [185] } \\
-\downarrow \text { in prefrontal areas and } \downarrow \text { right prefrontal cortex } \\
\text { negatively correlated with fatigue severity } \\
\text { NCT02305264: ongoing trial recruiting patients } \\
\text { with relapsing and progressive MS; } \\
\text { characterizing }{ }^{18} \text { F-FDG in WM inflammatory } \\
\text { cells }\end{array}$ \\
\hline $\begin{array}{l}\text { Neuronal and axonal } \\
\text { degeneration } \\
\mathrm{GABA}_{\mathrm{A}}-\mathrm{R} \\
{ }^{18} \mathrm{C} \text { - and }{ }^{18} \mathrm{~F} \text {-flumazenil }\end{array}$ & $\begin{array}{l}18 \mathrm{MS}(9 \mathrm{SP} / \mathrm{PP}, 9 \mathrm{RR})[186] \\
-\downarrow \text { in cortical and deep GM in both relapsing and } \\
\text { progressive } \\
-\downarrow \text { correlated with T2LV and cognitive } \\
\text { performance } \\
\text { NCT01651520: ongoing trial recruiting patients } \\
\text { with early MS to quantify cortical and deep GM } \\
\text { neuronal loss. }\end{array}$ \\
\hline
\end{tabular}

$\downarrow \uparrow=$ decreased or increased uptake, respectively; TPSO = translocator protein; $\mathrm{HC}=$ healthy controls; $\mathrm{GdE}=$ gadolinium-enhancing lesions; $\mathrm{NAWM}=$ normal-appearing white matter; $\mathrm{RR}=$ relapsing remitting; $\mathrm{SP}$ $=$ secondary progressive; EDSS $=$ Expanded Disability Status Scale; WM $=$ white matter $\mathrm{PP}=$ primary progressive; $\mathrm{CIS}=$ clinically isolated syndrome; $\mathrm{GM}=$ gray matter; $\mathrm{SPMS}=$ secondary progressive $\mathrm{MS} ; \mathrm{CNS}=$ central nervous system; ${ }^{18} \mathrm{~F}-\mathrm{FDG}=$ fludeoxyglucose; $\mathrm{T} 2 \mathrm{LV}=\mathrm{T} 2$ lesion volume; $\mathrm{GABA}_{\mathrm{A}}-\mathrm{R}=\gamma$ - aminobutyric acid A receptor

cholinergic neurons previously described in patients with MS [187].

Amyloid tracers $\left({ }^{11} \mathrm{C}\right.$-PiB and ${ }^{18} \mathrm{~F}$-florbetaben) studied in dementia also correlate with $\mathrm{T} 2$ lesions in patients with MS and may correlate with demyelination $[175,177]$. Whether their uptake in WM is nonspecific or reflects $\beta$-amyloid pathology in MS is yet unknown. The ${ }^{11} \mathrm{C}-\mathrm{MeDAS}$ tracer has been studied in animal models of demyelination [lysolecithin 
[188], experimental autoimmune encephalomyelitis (EAE) [189], and cuprizone [190] and shows promise in improving detection of myelin.

Microglial activation has been characterized by uptake of ligands targeting the translocator protein, also known as the peripheral benzodiazepine receptor, and the ${ }^{11} \mathrm{C}$-TMSX ligand, which selectively binds to the A2A adenosine receptor. TSPO is expressed in activated microglia and reactive astrocytes [191], whereas ${ }^{11} \mathrm{C}$-TMSX is expressed throughout the central nervous system [192] and is upregulated in activated microglia in vitro [193]. In patients with CIS, the translocator protein tracer ${ }^{11} \mathrm{C}$-PK11195 is increased in T2 lesions, NAWM, and deep GM versus controls, and correlates with disability and risk of MS in 2 years [166]. TSPO uptake is increased in GdE lesions [170] and NAWM in patients with MS. TSPO levels also parallel progression [163] and atrophy [162]. Treatment with glatiramer acetate decreases its uptake globally in both GM and WM [167]. The ${ }^{11} \mathrm{C}-\mathrm{TMSX}$ ligand is also higher in NAWM and correlates with EDSS scores [173]. Chronic lesions with T1 hypointensity in patients with SPMS also show perilesional TSPO uptake which parallels microglial/macrophage (CD68) immunohistochemistry on chronic MS tissue [194] and in EAE [195]. TSPO uptake parallels neuronal loss (NAA with MRS), GM atrophy, and disability $[171,196]$. Many other novel TSPO ligands in development for MS are currently being studied (Table 2).

Benzyl ${ }^{11} \mathrm{C}$-acetate [197] and its ${ }^{18} \mathrm{~F}$ derivative [198] have been proposed to label astrocytes as acetate accumulates in astrocytes in MS lesions [174]. With greater recognition of the role of astrocytes in MS, development of similar in vivo ligands will prove useful in determining efficacy of targeted therapeutics.

Glucose metabolism with fludeoxyglucose has been studied to determine whether metabolic dysfunction precedes demyelination. Metabolic activity is also hypothesized to predict symptoms such as cognitive impairment or fatigue. In animal models of MS, no differences with EAE [199] or with lysolecithin [188] in the brain have been noted, but fludeoxyglucose is increased in spinal cord lesions from EAE [200]. Cognitive impairment is associated with glucose hypometabolism in cortical regions [183], as well as the thalamus and other deep GM structures [183, 184]. Fatigue severity is associated with glucose hypometabolism in the prefrontal cortex [185] and thalamus [201].

Multiple ligands with novel targets have been developed, tested in vitro, or tested in vivo in animal models of demyelination (cuprizone [190], lysolecithin [202], EAE [203]). The high costs associated with producing radiopharmaceutical agents and the availability of cyclotrons present an obvious limitation but will likely diminish with its further use. As with other advanced imaging techniques, PET imaging hopes to increase the specificity of identifying MS lesions and understanding the underlying biology.

\section{Myelin Measures}

Water constitutes approximately $40 \%$ of myelin, is thought to be present between its layers, and can be imaged from short $\mathrm{T} 2$ relaxation components in $<50 \mathrm{~ms}$ [204]. Myelin water fraction (MWF), a ratio of myelin water to total water [205], correlates with myelin density histologically (Luxol fast blue) [206]. Regions with intermediate T2 signal between NAWM and T2 lesions, termed "dirty-appearing white matter", were also found to have decreased MWF corresponding to decreased myelin (Luxol fast blue) and axonal density (Bielschowsky stain) [207].

While initially time consuming, MWF can now be acquired in feasible acquisition times [208] and whole-brain coverage using fast acquisition with spiral trajectory and T2prep, or multicomponent-driven equilibrium single pulse observation of $\mathrm{T} 1$ and $\mathrm{T} 2$ can be attained in 4 [209] or $14 \mathrm{~min}$ [210], respectively. Another approach to improve MWF resolution, direct visualization of short transverse relaxation time component, suppresses long $\mathrm{T} 1$ signal leaving a short $\mathrm{T} 2 *$ signal in the myelin water range and can be acquired in a very short time (3 $\mathrm{min})$ [211].

MWF in MS lesions and NAWM correlates with disability measures, discriminates MS types, and can be used to track longitudinally evolution of lesions. Lesions contain $6 \%$ more water but $52 \%$ less MWF, on average, versus control WM. MS NAWM contains 2\% more water and $16 \%$ less MWF versus control WM [212]. NAWM MWF in PPMS is decreased by $6 \%$ versus controls and correlates with EDSS [210] and 9-hole peg test [213]. Lesional MWF varies between GdE and T2 lesions, and T1 black holes [208] and differences are hypothesized to be due to pathologic variations of the lesion types. MWF may be useful as an outcome measure for therapeutics that promote repair as it is sensitive to recovery following GdE [214].

Myelin imaging can be supplemented by measurement of axonal content, estimated with MRI diffusion measures. The myelin G-ratio (axon diameter/axon + myelin diameter) can be directly measured with electron microscopy and an in vivo surrogate can be obtained with MRI by calculating the myelin and axonal volume fractions $[215,216]$.

\section{Spinal Cord Imaging}

Spinal cord MRI can aid in the diagnosis of MS [217], assist in risk stratification in RIS [218] or CIS [219], and monitor for disease activity on treatment. Inherent difficulties of MR spinal cord imaging include small cross-sectional size, physiological motion, and the local environment of the cord with surrounding bone structure [220]. These conditions have made implementation of spinal cord imaging difficult in clinical trials. The MAGNISMS group has made recommendations for spinal cord clinical acquisition parameters to include both sagittal and axial 
planes with 1) T2; 2) short T1 inversion recovery or DIR [221]; and 3) postcontrast T1 [217]. Other methods, such as T1 3D magnetization-prepared rapid acquisition with gradient echo [222] and proton density fast spin echo [223], may add value in lesion detection. Spinal cord lesions may be missed without axial views [224] or including T2 with either short T1 inversion recovery or DIR [221, 225]. Novel methods strive to image the entire cord efficiently [226] as the thoracic region, often ignored, includes $40 \%$ of spinal cord lesion burden [227]. For clinical trials, imaging of the cervical spine is probably the best candidate for a multicenter outcome measure.

Spinal cord atrophy measures, such as cross-sectional area, have been studied extensively in almost all forms of MS and are good candidates for clinical trials. Cervical cord atrophy in CIS [228] is independently associated with accrual of disability [229] and suggests axonal loss and demyelination [230] occur early in the disease course. The cervical cord is extensively imaged in MS and is an attractive outcome measure as its atrophy correlates with disability, particularly in progressive MS [231, 232]. Reproducible medulla oblongata volumes [233] or crosssectional area at $\mathrm{C} 2$ [234] seem to follow this trend and could be a surrogate for cervical cord involvement in clinical trials. GM lesions may be more readily detectible in the cord than in the cortex [235]. GM loss occurs in both cervical [236] and thoracic [237] segments, is more pronounced in progressive courses [238], correlates with disability, and is independent of WM atrophy in relapsing MS [236]. Accrual of cervical cord lesions increases the odds of thoracic cord lesions [239] and overall cord lesion burden are associated with certain $H L A-D R B 1$ alleles [240] and risk loci [241]. Measuring loss of cord volume to monitor efficacy of neuroprotective therapeutics [242], such as IFN- $\beta 1 \alpha$ [243], IFN- $\beta 1 \mathrm{~b}$ [244], and glatiramer acetate [245] have been attempted in small trials.

Multiple advanced imaging techniques have been applied to the spinal cord in preliminary studies [246], and hold promise for future clinical trials. Advanced measures have been useful in distinguishing differences in clinical phenotypes [247] and correlating with disability measures. DTI has been extensively applied to the spinal cord in normal-appearing and lesional regions, correlates with demyelination histologically [248], and can be used to track recovery longitudinally [249]. These changes reflect global changes in the disease as they also correlate with retinal nerve fiber layer thickness [250]. Decrease in normal-appearing cervical cord FA is specific and sensitive in distinguishing MS from controls [251], and is more markedly decreased in progressive than in relapsing courses [252]. Spinal cord GM is increasingly involved in comparing CIS, RRMS, and SPMS with respect to FA (decreased suggesting demyelination), RD (increased suggesting demyelination), and MD (increased with injury) [253].

Other methods include MWF, MRS, MT, and fMRI. MWF, an estimate of myelination $[254,255]$, is reduced in the cervical cord of patients with progressive MS [213], and does not appear to change with glatiramer acetate after 2 years [256]. MRS is susceptible to artifact, low signal-to-noise ratio, and mostly limited to the cervical cord [257]. Some changes in mIns, NAA, and Cho have been found in patients with MS, albeit in small studies with variable results [258], and some association with disability [259]. MT in the spinal cord is associated with myelin and axonal density and can be acquired quantitatively the spinal cord with reasonable acquisition times [260]. Decrease in spinal cord MT is observed early in MS, involves both WM [261] and GM [262], correlates with disability [263], and appears to be more affected in the outer pial/subpial region in CIS, relapsing, and progressive MS versus controls [264]. MT reduction in the dorsal and lateral columns correlates with impaired vibratory sense and muscle power, respectively [261]. Lastly, fMRI has been used to characterize disability and typically shows diffuse cord recruitment with fatigue [265] and overactivation with tactile stimuli in relapsing [266], as well as progressive [75], courses.

\section{Leptomeningeal Enhancement}

Persistent enhancement of the leptomeninges may reflect populations of immunologic cells that may contribute to ongoing neurodegeneration, cortical demyelination, and cortical atrophy seen in MS [267]. Leptomeningeal enhancement (LME) has only recently been described in MS and T2 FLAIR postcontrast is more sensitive than $\mathrm{T} 1$ in detecting enhancement due to improved CSF contrast. LME is more prevalent in progressive MS and correlates with global and cortical atrophy [268]. The association between LME and cortical subpial demyelination and perivascular macrophages and $\mathrm{T}$ and $\mathrm{B}$ lymphocytes has been demonstrated in a small postmortem study [269].

Although LME occurs in 25\% [269, 270] of patients with MS, it is not specific. A similar pattern of proximity to vessels, nodular or linear shape, and supratentorial more than infratentorial location, is seen with other inflammatory/ infectious (human T-lymphotropic virus, HIV, Behçet's disease, Susac syndrome $[270,271]$ ) and noninflammatory/noninfectious conditions. Also, 4 of 65 female asymptomatic first-degree relatives of patients with MS have persistent LME [272]. There has been speculation, owing to the increased frequency of these lesions in PMS and their location, that these lesions may represent meningeal follicles and contribute to ongoing progression. It is possible this could be targeted and used as an outcome measure in trials, but validation is still required.

\section{Iron Imaging}

Iron is the most abundant trace metal in brain and is stored predominantly in oligodendrocytes and myelin [273], making it an attractive imaging contrast in MS. In active MS lesions, dying oligodendrocytes release iron, which accumulates in 
astrocytes, microglia/macrophages, and axons [274]. This process contributes to oxidative injury and mitochondrial dysfunction of axons, neurons, and glia in the lesional milieu [275]. Nonphagocytosing proinflammatory M1 macrophages/microglia accumulate iron at the edge of chronic active WM and cortical demyelinated lesions [276]. Iron contrast can be assessed on MRI with spin echo T1 or GRE and in tissue confirmed with immunohistochemistry (Perls' stain for iron and CD68 for microglia). Remarkably, chronically active lesions with rims are more likely to continue expanding, whereas chronically inactive lesions do not [277]. Rims are not only more common in active relapsing MS, but also present in SPMS [276, 278], and their persistence correlates with more tissue injury (T1 hypointensity) [279].

In addition to accumulation of iron in WM lesions [274, 276], in both CIS [280] and RRMS [281] iron accumulation is also found in deep GM. Deep GM iron content correlates with disability [282], WM tract injury by DTI metrics [283], and cognitive impairment [284, 285]. Over time, iron in NAWM decreases in MS, possibly because of glial uptake [274, 286].

There is a plethora of MRI techniques, each with their advantages and disadvantages, used to evaluate iron accumulation in vivo at $7 \mathrm{~T}$ [287]: T2 hypointensity [288], phase [289], transverse relaxivity (R2*) [290], T2*GRE [291], susceptibility-weighted imaging [292], T2* coupled with phase-dynamic contrast-enhanced T1 [293], magnetic field correlation [294], FLAIR* [295], 3D-T2*-angiography (3DESWAN) [296], quantitative susceptibility mapping (QSM), and inversion recovery-ultrashort echo time (concomitantly images myelin and iron [297]). Also, an exogenous method to evaluate iron uptake exists with ultra small (nano) super paramagnetic particles of iron oxide that are phagocytosed by active monocytes/microglia. These particles show promise in detecting more active lesions than gadolinium in pilot studies [298] and correlate with tissue injury in CIS [299, 300].

Of particular interest, QSM, has fewer artifacts than conventional imaging [301], advantages to phase imaging [289], correlates well with iron in microglia/macrophages [301], and can be used to longitudinally follow active lesions. QSM shows $90 \%$ sensitivity and specificity with GdE [302], starts to increase following a GdE lesion, and falls to baseline after 4 years [303]. Iron accumulation in the deep GM by QSM correlates with cognitive impairment [304] and impaired ability to suppress task-irrelevant information (inhibitory control) [305].

Because inflammation precedes and continues following GdE, QSM may prove to be an invaluable complementary tool to monitor inflammation. Detection of rimmed lesions carries the potential to supplement established measures of "activity" (new/enlarging T2 or GdE lesions) without the need for exogenous contrast agents. Furthermore, it may be possible to discriminate MS from microvascular disease [295] or NMOSD by the appearance of central veins, hypointense rims [306], and deep GM iron accumulation [296].
Overlap in the appearance of MS lesions with mimics, such as cerebral small vessel disease or migraine, present a challenge in clinical trials. The T2 lesion volume attributable to MS can potentially be misrepresented by comorbidities, particularly early in the MS disease course. The North American Imaging in Multiple Sclerosis Cooperative noted improved visualization of central vessels, a feature associated with demyelinating lesions to help discriminate MS lesions, by incorporating T2* and FLAIR (FLAIR*) [307, 308].

Iron imaging may represent a suitable clinical trial outcome measure especially for therapies that target iron metabolism or microglia. Future trials which use medications that target iron or microglia may use iron MRI measures as intermediate outcomes.

\section{Magnetic Resonance Fingerprinting}

Magnetic resonance fingerprinting (MRF) can collect wholebrain quantitative T1, T2, and spin density images in under 5 min by pseudo-random acquisition of flip angle and repetition, echo, and inversion times [309]. This novel technique is able to discriminate healthy controls from patients with MS and note differences between patients with SPMS and RRMS with respect to T1 and NAWM [310]. Furthermore, T1 and T2 values in particular regions correlate with disability measures including MS Functional Composite and Expanded Disability Status Scale scores [310]. The quantitative nature of this method makes it of particular interest in multicenter clinical trials using different MRI scanners. Ongoing studies are looking to characterize MRF measures in the thalamus, acquire MRF at 7 $\mathrm{T}$, and include chemical exchange characteristics with sensitivity to myelin content (unpublished work and [311]).

\section{Conclusions}

Advanced MRI imaging techniques in MS are rapidly evolving and will only continue to increase in their value as a surrogate in vivo biomarker for inflammation and neurodegeneration. Although many of these tools still require validation and development for multicenter application given they may have been restricted to smaller studies, their usefulness in clinical trials and practice will be of great value. The development of therapeutics that target specific pathogenic mechanisms will require these techniques to evaluate their efficacy as outcome measures.

\section{References}

1. Sormani MP, Bruzzi P. MRI lesions as a surrogate for relapses in multiple sclerosis: a meta-analysis of randomised trials. Lancet Neurol 2013;12(7):669-676. 
2. Kaunzner UW, Al-Kawaz M, Gauthier SA. Defining disease activity and response to therapy in MS. Curr Treat Options Neurol 2017;19(5):20. doi:10.1007/s11940-017-0454-5.

3. van Walderveen MA, Kamphorst W, Scheltens P, et al. Histopathologic correlate of hypointense lesions on T1-weighted spin-echo MRI in multiple sclerosis. Neurology 1998;50(5):12821288 .

4. Tam RC, Traboulsee A, Riddehough A, Sheikhzadeh F, Li DK. The impact of intensity variations in T1-hypointense lesions on clinical correlations in multiple sclerosis. Mult Scler 2011;17(8): 949-957.

5. Gabr RE, Hasan KM, Haque ME, Nelson FM, Wolinsky JS, Narayana PA. Optimal combination of FLAIR and T2-weighted MRI for improved lesion contrast in multiple sclerosis. J Magn Reson Imaging 2016;44(5):1293-1300.

6. Obusez EC, Lowe M, Oh SH, et al. 7T MR of intracranial pathology: Preliminary observations and comparisons to $3 \mathrm{~T}$ and $1.5 \mathrm{~T}$. NeuroImage 2016 Nov 30

7. Saake M, Langner S, Schwenke C, et al. MRI in multiple sclerosis: an intra-individual, randomized and multicentric comparison of gadobutrol with gadoterate meglumine at $3 \mathrm{~T}$. Eur Radiol 2016;26(3):820-828.

8. Fisher E, Chang A, Fox RJ, et al. Imaging correlates of axonal swelling in chronic multiple sclerosis brains. Ann Neurol 2007;62(3):219-228.

9. Vollmer T, Signorovitch J, Huynh L, et al. The natural history of brain volume loss among patients with multiple sclerosis: a systematic literature review and meta-analysis. J Neurol Sci 2015;357(1-2):8-18.

10. Zivadinov R, Uher T, Hagemeier J, et al. A serial 10-year followup study of brain atrophy and disability progression in RRMS patients. Mult Scler 2016;22(13):1709-1718.

11. Aubert-Broche B, Fonov V, Narayanan S, et al. Onset of multiple sclerosis before adulthood leads to failure of age-expected brain growth. Neurology 2014;83(23):2140-2146.

12. Jacobsen C, Hagemeier J, Myhr KM, et al. Brain atrophy and disability progression in multiple sclerosis patients: a 10-year follow-up study. J Neurol Neurosurg Psychiatry 2014;85(10):11091115.

13. Mellergard J, Tisell A, Blystad I, et al. Cerebrospinal fluid levels of neurofilament and tau correlate with brain atrophy in natalizumab-treated multiple sclerosis. Eur J Neurol 2017;24(1): 112-121.

14. Chataway J, Schuerer N, Alsanousi A, et al. Effect of high-dose simvastatin on brain atrophy and disability in secondary progressive multiple sclerosis (MS-STAT): a randomised, placebo-controlled, phase 2 trial. Lancet 2014;383(9936):2213-2221.

15. Barkhof F, Scheltens P, Frequin ST, et al. Relapsing-remitting multiple sclerosis: sequential enhanced MR imaging vs clinical findings in determining disease activity. AJR Am J Roentgenol 1992;159(5):1041-1047.

16. Willoughby EW, Grochowski E, Li DK, Oger J, Kastrukoff LF, Paty DW. Serial magnetic resonance scanning in multiple sclerosis: a second prospective study in relapsing patients. Ann Neurol 1989;25(1):43-49.

17. Calabrese M, De Stefano N, Atzori M, et al. Detection of cortical inflammatory lesions by double inversion recovery magnetic resonance imaging in patients with multiple sclerosis. Arch Neurol 2007;64(10):1416-1422.

18. Geurts JJ, Calabrese M, Fisher E, Rudick RA. Measurement and clinical effect of grey matter pathology in multiple sclerosis. Lancet Neurol 2012;11(12):1082-1092.

19. Roosendaal SD, Moraal B, Vrenken H, et al. In vivo MR imaging of hippocampal lesions in multiple sclerosis. J Magn Reson Imaging 2008;27(4):726-731.
20. Louapre C, Govindarajan ST, Gianni C, et al. The association between intra- and juxta-cortical pathology and cognitive impairment in multiple sclerosis by quantitative $\mathrm{T} 2 *$ mapping at $7 \mathrm{~T}$ MRI. NeuroImage Clin 2016;12:879-886.

21. Kilsdonk ID, Jonkman LE, Klaver R, et al. Increased cortical grey matter lesion detection in multiple sclerosis with $7 \mathrm{~T}$ MRI: a postmortem verification study. Brain 2016;139(Pt 5):1472-1481.

22. Seewann A, Kooi EJ, Roosendaal SD, et al. Postmortem verification of MS cortical lesion detection with 3D DIR. Neurology 2012;78(5):302-308.

23. Favaretto A, Poggiali D, Lazzarotto A, Rolma G, Causin F, Gallo $\mathrm{P}$. The parallel analysis of phase sensitive inversion recovery (PSIR) and double inversion recovery (DIR) images significantly improves the detection of cortical lesions in multiple sclerosis (MS) since clinical onset. PLOS ONE 2015;10(5):e0127805.

24. Futatsuya K, Kakeda S, Yoneda T, et al. Juxtacortical lesions in multiple sclerosis: assessment of gray matter involvement using phase difference-enhanced imaging (PADRE). Magn Reson Med Sci 2016;15(4):349-354.

25. Nelson F, Poonawalla A, Hou P, Wolinsky JS, Narayana PA. 3D MPRAGE improves classification of cortical lesions in multiple sclerosis. Mult Scler 2008;14(9):1214-1219.

26. Harrison DM, Roy S, Oh J, et al. Association of cortical lesion burden on 7-T magnetic resonance imaging with cognition and disability in multiple sclerosis. JAMA Neurol 2015;72(9):10041012.

27. Horakova D, Dwyer MG, Havrdova E, et al. Gray matter atrophy and disability progression in patients with early relapsingremitting multiple sclerosis: a 5-year longitudinal study. J Neurol Sci 2009;282(1-2):112-119.

28. Moccia M, Quarantelli M, Lanzillo R, et al. Grey:white matter ratio at diagnosis and the risk of 10-year multiple sclerosis progression. Eur J Neurol 2017;24(1):195-204.

29. Zivadinov R, Havrdova E, Bergsland N, et al. Thalamic atrophy is associated with development of clinically definite multiple sclerosis. Radiology 2013;268(3):831-841.

30. Eshaghi A, Wottschel V, Cortese R, et al. Gray matter MRI differentiates neuromyelitis optica from multiple sclerosis using random forest. Neurology 2016;87(23):2463-2470.

31. Bergsland N, Zivadinov R, Dwyer MG, Weinstock-Guttman B, Benedict RH. Localized atrophy of the thalamus and slowed cognitive processing speed in MS patients. Mult Scler 2016;22(10): 1327-1336.

32. Mahajan K, Nakamura, K, Vignos, M, et al. Thalamic MRI and histopathologic correlations in advanced multiple sclerosis. Neurology 2017;88(Suppl.S2.004).

33. Song SK, Yoshino J, Le TQ, et al. Demyelination increases radial diffusivity in corpus callosum of mouse brain. NeuroImage 2005;26(1):132-140.

34. Song SK, Sun SW, Ramsbottom MJ, Chang C, Russell J, Cross $\mathrm{AH}$. Dysmyelination revealed through MRI as increased radial (but unchanged axial) diffusion of water. NeuroImage 2002;17(3):1429-1436.

35. O'Donnell LJ, Westin CF. An introduction to diffusion tensor image analysis. Neurosurg Clin North Am 2011;22(2):185-196.

36. Schmierer K, Wheeler-Kingshott CA, Boulby PA, et al. Diffusion tensor imaging of post mortem multiple sclerosis brain. NeuroImage 2007;35(2):467-477.

37. Patel SA, Hum BA, Gonzalez CF, Schwartzman RJ, Faro SH, Mohamed FB. Application of voxelwise analysis in the detection of regions of reduced fractional anisotropy in multiple sclerosis patients. J Magn Reson Imaging 2007;26(3):552-556.

38. Poonawalla AH, Hasan KM, Gupta RK, et al. Diffusion-tensor MR imaging of cortical lesions in multiple sclerosis: initial findings. Radiology 2008;246(3):880-886. 
39. Rocca MA, Preziosa P, Mesaros S, et al. Clinically isolated syndrome suggestive of multiple sclerosis: dynamic patterns of gray and white matter changes-a 2-year MR imaging study. Radiology 2016;278(3):841-853.

40. Rovaris M, Bozzali M, Iannucci G, et al. Assessment of normalappearing white and gray matter in patients with primary progressive multiple sclerosis: a diffusion-tensor magnetic resonance imaging study. Arch Neurol 2002;59(9):1406-1412.

41. Oreja-Guevara C, Rovaris M, Iannucci G, et al. Progressive gray matter damage in patients with relapsing-remitting multiple sclerosis: a longitudinal diffusion tensor magnetic resonance imaging study. Arch Neurol 2005;62(4):578-584.

42. Chen J, Zhou C, Zhu L, et al. Magnetic resonance diffusion tensor imaging for occult lesion detection in multiple sclerosis. Exp Ther Med 2017;13(1):91-96.

43. Tovar-Moll F, Evangelou IE, Chiu AW, et al. Thalamic involvement and its impact on clinical disability in patients with multiple sclerosis: a diffusion tensor imaging study at 3T. AJNR Am J Neuroradiol 2009;30(7):1380-1386.

44. Deppe M, Kramer J, Tenberge JG, et al. Early silent microstructural degeneration and atrophy of the thalamocortical network in multiple sclerosis. Hum Brain Mapp 2016;37(5):1866-1879.

45. Rocca MA, Cercignani M, Iannucci G, Comi G, Filippi M. Weekly diffusion-weighted imaging of normal-appearing white matter in MS. Neurology 2000;55(6):882-884.

46. Ontaneda D, Sakaie K, Lin J, et al. Identifying the start of multiple sclerosis injury: a serial DTI study. J Neuroimaging 2014;24(6): 569-576.

47. Chiang GC, Pinto S, Comunale JP, Gauthier SA. Gadoliniumenhancing lesions lead to decreases in white matter tract fractional anisotropy in multiple sclerosis. J Neuroimaging 2016;26(3):289295.

48. Klistorner A, Wang C, Fofanova V, et al. Diffusivity in multiple sclerosis lesions: At the cutting edge? NeuroImage Clin 2016;12: 219-226.

49. Naismith RT, Xu J, Tutlam NT, et al. Increased diffusivity in acute multiple sclerosis lesions predicts risk of black hole. Neurology 2010;74(21):1694-1701.

50. Ontaneda D, Sakaie K, Lin J, et al. Measuring brain tissue integrity during 4 years using diffusion tensor imaging. AJNR Am J Neuroradiol 2017;38(1):31-38.

51. Louapre C, Govindarajan ST, Gianni C, et al. Is the relationship between cortical and white matter pathologic changes in multiple sclerosis spatially specific? A multimodal 7-T and 3-T MR imaging study with surface and tract-based analysis. Radiology 2016;278(2):524-535.

52. Keser Z, Hasan KM, Mwangi B, et al. Limbic pathway correlates of cognitive impairment in multiple sclerosis. J Neuroimaging 2017;27(1):37-42.

53. Yu HJ, Christodoulou C, Bhise V, et al. Multiple white matter tract abnormalities underlie cognitive impairment in RRMS. NeuroImage 2012;59(4):3713-3722.

54. Planche V, Ruet A, Coupe P, et al. Hippocampal microstructural damage correlates with memory impairment in clinically isolated syndrome suggestive of multiple sclerosis. Mult Scler 2016 Oct 15.

55. Hubbard EA, Wetter NC, Sutton BP, Pilutti LA, Motl RW. Diffusion tensor imaging of the corticospinal tract and walking performance in multiple sclerosis. J Neurol Sci 2016;363:225231.

56. Prosperini L, Fanelli F, Petsas N, et al. Multiple sclerosis: changes in microarchitecture of white matter tracts after training with a video game balance board. Radiology 2014;273(2):529-538.

57. Brambilla L, Rossi Sebastiano D, Aquino D, et al. Early effect of dalfampridine in patients with MS: a multi-instrumental approach to better investigate responsiveness. J Neurol Sci 2016;368:402407.

58. Senda J, Watanabe H, Endo K, et al. Active brain changes after initiating fingolimod therapy in multiple sclerosis patients using individual voxel-based analyses for diffusion tensor imaging. Nagoya J Med Sci 2016;78(4):455-463.

59. Wiebenga OT, Schoonheim MM, Hulst HE, et al. White matter diffusion changes during the first year of natalizumab treatment in relapsing-remitting multiple sclerosis. AJNR Am J Neuroradiol 2016;37(6):1030-1037.

60. Ratzer R, Iversen P, Bornsen L, et al. Monthly oral methylprednisolone pulse treatment in progressive multiple sclerosis. Mult Scler.2016;22(7):926-934.

61. Fox RJ, Coffey CS, Cudkowicz ME, et al. Design, rationale, and baseline characteristics of the randomized double-blind phase II clinical trial of ibudilast in progressive multiple sclerosis. Contemp Clin Trials 2016;50:166-177.

62. Lin TH, Chiang CW, Perez-Torres CJ, et al. Diffusion MRI quantifies early axonal loss in the presence of nerve swelling. J Neuroinflammation 2017;14(1):78.

63. Schneider T, Brownlee W, Zhang H, Ciccarelli O, Miller DH, Wheeler-Kingshott CG. Sensitivity of multi-shell NODDI to multiple sclerosis white matter changes: a pilot study. Funct Neurol 2017;32(2):97-101.

64. Ogawa S, Lee TM, Kay AR, Tank DW. Brain magnetic resonance imaging with contrast dependent on blood oxygenation. Proc Natl Acad Sci U S A 1990;87(24):9868-9872.

65. Faivre A, Rico A, Zaaraoui W, et al. Assessing brain connectivity at rest is clinically relevant in early multiple sclerosis. Mult Scler 2012;18(9):1251-1258.

66. Roosendaal SD, Schoonheim MM, Hulst HE, et al. Resting state networks change in clinically isolated syndrome. Brain 2010;133(Pt 6):1612-1621.

67. Liu Y, Duan Y, Liang P, et al. Baseline brain activity changes in patients with clinically isolated syndrome revealed by resting-state functional MRI. Acta Radiol 2012;53(9):1073-1078.

68. Giorgio A, Stromillo ML, De Leucio A, et al. Appraisal of brain connectivity in radiologically isolated syndrome by modeling imaging measures. J Neurosci 2015;35(2):550-558.

69. Rocca MA, Colombo B, Falini A, et al. Cortical adaptation in patients with MS: a cross-sectional functional MRI study of disease phenotypes. Lancet Neurol 2005;4(10):618-626.

70. Faivre A, Robinet E, Guye M, et al. Depletion of brain functional connectivity enhancement leads to disability progression in multiple sclerosis: a longitudinal resting-state fMRI study. Mult Scler 2016;22(13):1695-1708.

71. Liu Y, Liang P, Duan Y, et al. Altered thalamic functional connectivity in multiple sclerosis. Eur J Radiol 2015;84(4):703-708.

72. Filippi M, Rocca MA, Mezzapesa DM, et al. Simple and complex movement-associated functional MRI changes in patients at presentation with clinically isolated syndromes suggestive of multiple sclerosis. Hum Brain Mapp 2004;21(2):108-117.

73. Giorgio A, Portaccio E, Stromillo ML, et al. Cortical functional reorganization and its relationship with brain structural damage in patients with benign multiple sclerosis. Mult Scler 2010;16(11): 1326-1334.

74. Rocca MA, Matthews PM, Caputo D, et al. Evidence for widespread movement-associated functional MRI changes in patients with PPMS. Neurology 2002;58(6):866-872.

75. Agosta F, Valsasina P, Absinta M, Sala S, Caputo D, Filippi M. Primary progressive multiple sclerosis: tactile-associated functional MR activity in the cervical spinal cord. Radiology 2009;253(1): 209-215.

76. Audoin B, Reuter F, Duong MV, et al. Efficiency of cognitive control recruitment in the very early stage of multiple sclerosis: a one-year fMRI follow-up study. Mult Scler 2008;14(6):786-792. 
77. Sbardella E, Upadhyay N, Tona F, et al. Dentate nucleus connectivity in adult patients with multiple sclerosis: functional changes at rest and correlation with clinical features. Mult Scler 2017;23(4):546-555.

78. Koini M, Filippi M, Rocca MA, et al. Correlates of executive functions in multiple sclerosis based on structural and functional MR imaging: insights from a multicenter study. Radiology 2016;280(3):869-879.

79. Nelson F, Akhtar MA, Zuniga E, et al. Novel fMRI working memory paradigm accurately detects cognitive impairment in multiple sclerosis. Mult Scler 2017;23:836-847.

80. Vacchi L, Rocca MA, Meani A, et al. Working memory network dysfunction in relapse-onset multiple sclerosis phenotypes: a clinical-imaging evaluation. Mult Scler 2017;23(4):577-587.

81. Schoonheim MM, Geurts JJ, Landi D, et al. Functional connectivity changes in multiple sclerosis patients: a graph analytical study of MEG resting state data. Hum Brain Mapp 2013;34(1): 52-61.

82. Specogna I, Casagrande F, Lorusso A, et al. Functional MRI during the execution of a motor task in patients with multiple sclerosis and fatigue. Radiol Med 2012;117(8):1398-1407.

83. Pravata E, Zecca C, Sestieri C, et al. Hyperconnectivity of the dorsolateral prefrontal cortex following mental effort in multiple sclerosis patients with cognitive fatigue. Mult Scler 2016;22(13): 1665-1675.

84. DeLuca J, Genova HM, Hillary FG, Wylie G. Neural correlates of cognitive fatigue in multiple sclerosis using functional MRI. J Neurol Sci 2008;270(1-2):28-39.

85. Bosnell R, Wegner C, Kincses ZT, et al. Reproducibility of fMRI in the clinical setting: implications for trial designs. NeuroImage 2008:42(2):603-610.

86. Hulst HE, Goldschmidt T, Nitsche MA, et al. rTMS affects working memory performance, brain activation and functional connectivity in patients with multiple sclerosis. J Neurol Neurosurg Psychiatry 2017;88:386-394.

87. De Giglio L, Tona F, De Luca F, et al. Multiple sclerosis: changes in thalamic resting-state functional connectivity induced by a home-based cognitive rehabilitation program. Radiology 2016;280(1):202-211.

88. Huiskamp M, Dobryakova E, Wylie GD, DeLuca J, Chiaravalloti ND. A pilot study of changes in functional brain activity during a working memory task after mSMT treatment: the MEMREHAB trial. Mult Scler Relat Disord 2016;7:76-82.

89. Pinter D, Beckmann C, Koini M, et al. Reproducibility of resting state connectivity in patients with stable multiple sclerosis. PLOS ONE 2016;11(3):e0152158.

90. Jovicich J, Minati L, Marizzoni M, et al. Longitudinal reproducibility of default-mode network connectivity in healthy elderly participants: a multicentric resting-state fMRI study. NeuroImage 2016;124(Pt A):442-454.

91. Costafreda SG, Brammer MJ, Vencio RZ, et al. Multisite fMRI reproducibility of a motor task using identical MR systems. J Magn Reson Imaging 2007;26(4):1122-1126.

92. Wolff SD, Balaban RS. Magnetization transfer contrast (MTC) and tissue water proton relaxation in vivo. Magn Reson Med 1989;10(1):135-144.

93. Schmierer K, Scaravilli F, Altmann DR, Barker GJ, Miller DH. Magnetization transfer ratio and myelin in postmortem multiple sclerosis brain. Ann Neurol 2004;56(3):407-415.

94. Chen JT, Kuhlmann T, Jansen GH, et al. Voxel-based analysis of the evolution of magnetization transfer ratio to quantify remyelination and demyelination with histopathological validation in a multiple sclerosis lesion. NeuroImage 2007;36(4):11521158.

95. Pike GB, De Stefano N, Narayanan S, et al. Multiple sclerosis: magnetization transfer MR imaging of white matter before lesion appearance on T2-weighted images. Radiology 2000;215(3):824830.

96. Fernando KT, Tozer DJ, Miszkiel KA, et al. Magnetization transfer histograms in clinically isolated syndromes suggestive of multiple sclerosis. Brain 2005;128(Pt 12):2911-2925.

97. Iannucci G, Tortorella C, Rovaris M, Sormani MP, Comi G, Filippi M. Prognostic value of MR and magnetization transfer imaging findings in patients with clinically isolated syndromes suggestive of multiple sclerosis at presentation. AJNR Am J Neuroradiol 2000;21(6):1034-1038.

98. Brown JW, Pardini M, Brownlee WJ, et al. An abnormal periventricular magnetization transfer ratio gradient occurs early in multiple sclerosis. Brain 2017;140(Pt 2):387-398.

99. Laule C, Vavasour IM, Whittall KP, et al. Evolution of focal and diffuse magnetisation transfer abnormalities in multiple sclerosis. J Neurol 2003;250(8):924-931.

100. Agosta F, Rovaris M, Pagani E, Sormani MP, Comi G, Filippi M. Magnetization transfer MRI metrics predict the accumulation of disability 8 years later in patients with multiple sclerosis. Brain 2006;129(Pt 10):2620-2627.

101. Abdel-Fahim R, Mistry N, Mougin O, et al. Improved detection of focal cortical lesions using 7T magnetisation transfer imaging in patients with multiple sclerosis. Mult Scler Relat Disord 2014;3(2):258-265.

102. Faiss JH, Dahne D, Baum K, et al. Reduced magnetisation transfer ratio in cognitively impaired patients at the very early stage of multiple sclerosis: a prospective, multicenter, cross-sectional study. BMJ Open 2014;4(4):e004409.

103. Khalil M, Enzinger C, Langkammer C, et al. Cognitive impairment in relation to MRI metrics in patients with clinically isolated syndrome. Mult Scler 2011;17(2):173-180.

104. van den Elskamp IJ, Knol DL, Vrenken H, et al. Lesional magnetization transfer ratio: a feasible outcome for remyelinating treatment trials in multiple sclerosis. Mult Scler 2010;16(6):660-669.

105. Tao Y, Zhang X, Zivadinov R, et al. Immunologic and MRI markers of the therapeutic effect of IFN-beta-1a in relapsingremitting MS. Neurol Neuroimmunol Neuroinflamm 2015;2(6): e176.

106. Inglese $\mathrm{M}$, van Waesberghe $\mathrm{JH}$, Rovaris $\mathrm{M}$, et al. The effect of interferon beta- $1 \mathrm{~b}$ on quantities derived from MT MRI in secondary progressive MS. Neurology 2003;60(5):853-860.

107. Zivadinov R, Hussein S, Bergsland N, Minagar A, Dwyer MG. Magnetization transfer imaging of acute black holes in patients on glatiramer acetate. Front Biosci (Elite Ed.) 2012;4:1496-1504.

108. Arnold DL, Gold R, Kappos L, et al. Magnetization transfer ratio in the delayed-release dimethyl fumarate DEFINE study. J Neurol 2014;261(12):2429-2437.

109. Miller DH, Fox RJ, Phillips JT, et al. Effects of delayed-release dimethyl fumarate on MRI measures in the phase 3 CONFIRM study. Neurology 2015;84(11):1145-1152.

110. Romme Christensen J, Ratzer R, Bornsen L, et al. Natalizumab in progressive MS: results of an open-label, phase 2A, proof-ofconcept trial. Neurology 2014;82(17):1499-1507.

111. Zivadinov R, Dwyer MG, Hussein S, et al. Voxel-wise magnetization transfer imaging study of effects of natalizumab and IFNbeta-1a in multiple sclerosis. Mult Scler 2012;18(8):11251134.

112. Button T, Altmann D, Tozer D, et al. Magnetization transfer imaging in multiple sclerosis treated with alemtuzumab. Mult Scler 2013;19(2):241-244.

113. Schwartzbach CJ, Grove RA, Brown R, Tompson D, Then Bergh F, Arnold DL. Lesion remyelinating activity of GSK239512 versus placebo in patients with relapsing-remitting multiple sclerosis: a randomised, single-blind, phase II study. J Neurol 2017;264(2): 304-315. 
114. Al-Iedani O, Lechner-Scott J, Ribbons K, Ramadan S. Fast magnetic resonance spectroscopic imaging techniques in human brainapplications in multiple sclerosis. J Biomed Sci 2017;24(1):17.

115. Jain S, Sima DM, Sanaei Nezhad F, et al. Patch-based super-resolution of MR spectroscopic images: application to multiple sclerosis. Front Neurosci 2017;11:13.

116. Mathiesen HK, Tscherning T, Sorensen PS, et al. Multi-slice echoplanar spectroscopic MR imaging provides both global and local metabolite measures in multiple sclerosis. Magn Reson Med 2005;53(4):750-759.

117. Bitsch A, Bruhn H, Vougioukas V, et al. Inflammatory CNS demyelination: histopathologic correlation with in vivo quantitative proton MR spectroscopy. AJNR Am J Neuroradiol 1999;20(9): 1619-1627.

118. Orije J, Kara F, Guglielmetti C, et al. Longitudinal monitoring of metabolic alterations in cuprizone mouse model of multiple sclerosis using $1 \mathrm{H}$-magnetic resonance spectroscopy. NeuroImage 2015;114:128-135.

119. Bellmann-Strobl J, Stiepani H, Wuerfel J, et al. MR spectroscopy (MRS) and magnetisation transfer imaging (MTI), lesion load and clinical scores in early relapsing remitting multiple sclerosis: a combined cross-sectional and longitudinal study. Eur Radiol 2009;19(8):2066-2074.

120. De Stefano N, Narayanan S, Francis GS, et al. Evidence of axonal damage in the early stages of multiple sclerosis and its relevance to disability. Arch Neurol 2001;58(1):65-70.

121. Wu X, Hanson LG, Skimminge A, et al. Cortical N-acetyl aspartate is a predictor of long-term clinical disability in multiple sclerosis. Neurol Res 2014;36(8):701-708.

122. Rigotti DJ, Gonen O, Grossman RI, et al. Global N-acetylaspartate declines even in benign multiple sclerosis. AJNR Am J Neuroradiol 2011;32(1):204-209.

123. Narayanan S, Francis SJ, Sled JG, et al. Axonal injury in the cerebral normal-appearing white matter of patients with multiple sclerosis is related to concurrent demyelination in lesions but not to concurrent demyelination in normal-appearing white matter. NeuroImage 2006;29(2):637-642.

124. Vafaeyan H, Ebrahimzadeh SA, Rahimian N, et al. Quantification of diagnostic biomarkers to detect multiple sclerosis lesions employing (1)H-MRSI at 3T. Australas Phys Eng Sci Med 2015;38(4):611-618.

125. Moussallieh FM, Elbayed K, Chanson JB, et al. Serum analysis by $1 \mathrm{H}$ nuclear magnetic resonance spectroscopy: a new tool for distinguishing neuromyelitis optica from multiple sclerosis. Mult Scler 2014;20(5):558-565.

126. Pardini M, Botzkowski D, Muller S, et al. The association between retinal nerve fibre layer thickness and $\mathrm{N}$-acetyl aspartate levels in multiple sclerosis brain normal-appearing white matter: a longitudinal study using magnetic resonance spectroscopy and optical coherence tomography. Eur J Neurol 2016;23(12):1769-1774.

127. Chang L, Munsaka SM, Kraft-Terry S, Ernst T. Magnetic resonance spectroscopy to assess neuroinflammation and neuropathic pain. J Neuroimmune Pharmacol 2013;8(3):576-593.

128. Rovira A, Alonso J. 1H magnetic resonance spectroscopy in multiple sclerosis and related disorders. Neuroimaging Clin North Am 2013;23(3):459-474.

129. De Stefano N, Matthews PM, Antel JP, Preul M, Francis G, Arnold DL. Chemical pathology of acute demyelinating lesions and its correlation with disability. Ann Neurol 1995;38(6):901909.

130. Fu L, Matthews PM, De Stefano N, et al. Imaging axonal damage of normal-appearing white matter in multiple sclerosis. Brain 1998;121 (Pt 1):103-113.

131. Sarchielli P, Presciutti O, Pelliccioli GP, et al. Absolute quantification of brain metabolites by proton magnetic resonance spectroscopy in normal-appearing white matter of multiple sclerosis patients. Brain 1999;122:513-521.

132. Narayana PA, Doyle TJ, Lai D, Wolinsky JS. Serial proton magnetic resonance spectroscopic imaging, contrast-enhanced magnetic resonance imaging, and quantitative lesion volumetry in multiple sclerosis. Ann Neurol 1998;43(1):56-71.

133. Srinivasan R, Sailasuta N, Hurd R, Nelson S, Pelletier D. Evidence of elevated glutamate in multiple sclerosis using magnetic resonance spectroscopy at $3 \mathrm{~T}$. Brain 2005;128(Pt 5):10161025.

134. Srinivasan R, Ratiney H, Hammond-Rosenbluth KE, Pelletier D, Nelson SJ. MR spectroscopic imaging of glutathione in the white and gray matter at $7 \mathrm{~T}$ with an application to multiple sclerosis. Magn Reson Imaging 2010;28(2):163-170.

135. Inglese M, Li BS, Rusinek H, Babb JS, Grossman RI, Gonen O. Diffusely elevated cerebral choline and creatine in relapsingremitting multiple sclerosis. Magn Reson Med 2003;50(1):190195.

136. Tartaglia MC, Narayanan S, De Stefano N, et al. Choline is increased in pre-lesional normal appearing white matter in multiple sclerosis. J Neurol 2002;249(10):1382-1390.

137. Wattjes MP, Rovira A, Miller D, et al. Evidence-based guidelines: MAGNIMS consensus guidelines on the use of MRI in multiple sclerosis - establishing disease prognosis and monitoring patients. Nat Rev Neurol 2015;11(10):597-606.

138. De Stefano N, Filippi M, Miller D, et al. Guidelines for using proton MR spectroscopy in multicenter clinical MS studies. Neurology 2007;69(20):1942-1952.

139. Narayanan S, De Stefano N, Francis GS, et al. Axonal metabolic recovery in multiple sclerosis patients treated with interferon beta1b. J Neurol 2001;248(11):979-986.

140. Parry A, Corkill R, Blamire AM, et al. Beta-interferon treatment does not always slow the progression of axonal injury in multiple sclerosis. J Neurol 2003;250(2):171-178.

141. Sarchielli P, Presciutti O, Tarducci R, et al. 1H-MRS in patients with multiple sclerosis undergoing treatment with interferon beta1a: results of a preliminary study. J Neurol Neurosurg Psychiatry 1998;64(2):204-212.

142. Yetkin MF, Mirza M, Donmez H. Monitoring interferon beta treatment response with magnetic resonance spectroscopy in relapsing remitting multiple sclerosis. Medicine 2016;95(36):e4782.

143. Khan O, Seraji-Bozorgzad N, Bao F, et al. The relationship between brain MR spectroscopy and disability in multiple sclerosis: 20-year data from the U.S. Glatiramer Acetate Extension Study. J Neuroimaging 2017;27(1):97-106.

144. Sajja BR, Narayana PA, Wolinsky JS, Ahn CW. Longitudinal magnetic resonance spectroscopic imaging of primary progressive multiple sclerosis patients treated with glatiramer acetate: multicenter study. Mult Scler 2008;14(1):73-80.

145. Mellergard J, Tisell A, Dahlqvist Leinhard O, et al. Association between change in normal appearing white matter metabolites and intrathecal inflammation in natalizumab-treated multiple sclerosis. PLOS ONE 2012;7(9):e44739.

146. Wiebenga OT, Klauser AM, Schoonheim MM, et al. Enhanced axonal metabolism during early natalizumab treatment in relapsing-remitting multiple sclerosis. AJNR Am J Neuroradiol 2015;36(6):1116-1123.

147. Sedel F, Papeix C, Bellanger A, et al. High doses of biotin in chronic progressive multiple sclerosis: a pilot study. Mult Scler Relat Disord 2015;4(2):159-169.

148. Sijens PE, Mostert JP, Irwan R, Potze JH, Oudkerk M, De Keyser J. Impact of fluoxetine on the human brain in multiple sclerosis as quantified by proton magnetic resonance spectroscopy and diffusion tensor imaging. Psychiatry Res 2008;164(3):274-282. 
149. Trapp BD, Stys PK. Virtual hypoxia and chronic necrosis of demyelinated axons in multiple sclerosis. Lancet Neurol 2009;8(3):280-291.

150. Campbell GR, Worrall JT, Mahad DJ. The central role of mitochondria in axonal degeneration in multiple sclerosis. Mult Scler 2014;20(14):1806-1813.

151. Maudsley AA, Hilal SK. Biological aspects of sodium-23 imaging. Br Med Bull 1984;40(2):165-166.

152. Eisele P, Konstandin S, Griebe M, et al. Heterogeneity of acute multiple sclerosis lesions on sodium (23Na) MRI. Mult Scler 2016;22(8):1040-1047.

153. Inglese $\mathrm{M}$, Madelin $\mathrm{G}$, Oesingmann $\mathrm{N}$, et al. Brain tissue sodium concentration in multiple sclerosis: a sodium imaging study at 3 tesla. Brain 2010;133(Pt 3):847-857.

154. Zaaraoui W, Konstandin S, Audoin B, et al. Distribution of brain sodium accumulation correlates with disability in multiple sclerosis: a cross-sectional $23 \mathrm{Na}$ MR imaging study. Radiology 2012;264(3):859-867.

155. Maarouf A, Audoin B, Konstandin S, et al. Topography of brain sodium accumulation in progressive multiple sclerosis. MAGMA 2014;27(1):53-62.

156. Paling D, Solanky BS, Riemer F, et al. Sodium accumulation is associated with disability and a progressive course in multiple sclerosis. Brain 2013;136(Pt 7):2305-2317.

157. Biller A, Pflugmann I, Badde S, et al. Sodium MRI in multiple sclerosis is compatible with intracellular sodium accumulation and inflammation-induced hyper-cellularity of acute brain lesions. Sci Rep 2016;6:31269.

158. Petracca M, Vancea RO, Fleysher L, Jonkman LE, Oesingmann $\mathrm{N}$, Inglese M. Brain intra- and extracellular sodium concentration in multiple sclerosis: a 7 T MRI study. Brain 2016;139(Pt 3):795806.

159. Raftopoulos R, Hickman SJ, Toosy A, et al. Phenytoin for neuroprotection in patients with acute optic neuritis: a randomised, placebo-controlled, phase 2 trial. Lancet Neurol 2016;15(3):259-269.

160. Yang C, Hao Z, Zhang L, Zeng L, Wen J. Sodium channel blockers for neuroprotection in multiple sclerosis. Cochrane Database Syst Rev 2015(10):CD010422.

161. Debruyne JC, Versijpt J, Van Laere KJ, et al. PET visualization of microglia in multiple sclerosis patients using [11C]PK11195. Eur J Neurol 2003;10(3):257-264.

162. Versijpt J, Debruyne JC, Van Laere KJ, et al. Microglial imaging with positron emission tomography and atrophy measurements with magnetic resonance imaging in multiple sclerosis: a correlative study. Mult Scler 2005;11(2):127-134.

163. Politis M, Giannetti P, Su P, et al. Increased PK11195 PET binding in the cortex of patients with MS correlates with disability. Neurology 2012;79(6):523-530.

164. Rissanen E, Tuisku J, Rokka J, et al. In vivo detection of diffuse inflammation in secondary progressive multiple sclerosis using PET imaging and the radioligand (1)(1)C-PK11195. J Nucl Med 2014;55(6):939-944.

165. Giannetti P, Politis M, Su P, et al. Microglia activation in multiple sclerosis black holes predicts outcome in progressive patients: an in vivo [(11)C](R)-PK11195-PET pilot study. Neurobiol Dis 2014;65:203-210.

166. Giannetti P, Politis M, Su P, et al. Increased PK11195-PET binding in normal-appearing white matter in clinically isolated syndrome. Brain 2015;138(Pt 1):110-119.

167. Ratchford JN, Endres CJ, Hammoud DA, et al. Decreased microglial activation in MS patients treated with glatiramer acetate. J Neurol 2012;259(6):1199-1205.

168. Takano A, Piehl F, Hillert J, et al. In vivo TSPO imaging in patients with multiple sclerosis: a brain PET study with [18F]FEDAA1106. EJNMMI Res 2013;3(1):30.
169. Oh U, Fujita M, Ikonomidou VN, et al. Translocator protein PET imaging for glial activation in multiple sclerosis. J Neuroimmune Pharmacol 2011;6(3):354-361.

170. Park E, Gallezot JD, Delgadillo A, et al. (11)C-PBR28 imaging in multiple sclerosis patients and healthy controls: test-retest reproducibility and focal visualization of active white matter areas. Eur J Nucl Med Mol Imaging 2015;42(7):1081-1092.

171. Herranz E, Gianni C, Louapre C, et al. Neuroinflammatory component of gray matter pathology in multiple sclerosis. Ann Neurol 2016;80(5):776-790.

172. Vas A, Shchukin Y, Karrenbauer VD, et al. Functional neuroimaging in multiple sclerosis with radiolabelled glia markers: preliminary comparative PET studies with [11C]vinpocetine and [11C]PK11195 in patients. J Neurol Sci 2008;264(1-2):9-17.

173. Rissanen E, Virta JR, Paavilainen T, et al. Adenosine A2A receptors in secondary progressive multiple sclerosis: a [(11)C]TMSX brain PET study. J Cerebral Blood Flow Metab 2013;33(9):13941401.

174. Takata K, Kato H, Shimosegawa E, et al. 11C-acetate PET imaging in patients with multiple sclerosis. PLOS ONE 2014;9(11): e111598.

175. Stankoff B, Freeman L, Aigrot MS, et al. Imaging central nervous system myelin by positron emission tomography in multiple sclerosis using [methyl-(1)(1)C]-2-(4'-methylaminophenyl)- 6hydroxybenzothiazole. Ann Neurol 2011;69(4):673-680.

176. Bodini B, Veronese M, Garcia-Lorenzo D, et al. Dynamic imaging of individual remyelination profiles in multiple sclerosis. Ann Neurol 2016 Feb 18.

177. Matias-Guiu JA, Cabrera-Martin MN, Matias-Guiu J, et al. Amyloid PET imaging in multiple sclerosis: an (18)F-florbetaben study. BMC Neurol 2015;15:243.

178. Kindred JH, Koo PJ, Rudroff T. Glucose uptake of the spinal cord in patients with multiple sclerosis detected by (1)(8)Ffluorodeoxyglucose PET/CT after walking. Spinal Cord 2014;52(Suppl. 3):S11-S13.

179. Maffione AM, Rampin L, Grassetto G, L'Erario R, Colletti PM, Rubello D. 18F-FDG PET/CT in tumefactive multiple sclerosis. Clin Nucl Med 2014;39(8):750-751.

180. Bolcaen J, Acou M, Mertens K, et al. Structural and metabolic features of two different variants of multiple sclerosis: a PET/MRI study. J Neuroimaging 2013;23(3):431-436.

181. Derache N, Marie RM, Constans JM, Defer GL. Reduced thalamic and cerebellar rest metabolism in relapsing-remitting multiple sclerosis, a positron emission tomography study: correlations to lesion load. J Neurol Sci 2006;245(1-2):103-109.

182. Blinkenberg M, Jensen CV, Holm S, Paulson OB, Sorensen PS. A longitudinal study of cerebral glucose metabolism, MRI, and disability in patients with MS. Neurology 1999;53(1):149-153.

183. Blinkenberg M, Rune K, Jensen CV, et al. Cortical cerebral metabolism correlates with MRI lesion load and cognitive dysfunction in MS. Neurology 2000;54(3):558-564.

184. Paulesu E, Perani D, Fazio F, et al. Functional basis of memory impairment in multiple sclerosis: a[18F]FDG PET study. NeuroImage 1996;4(2):87-96.

185. Roelcke U, Kappos L, Lechner-Scott J, et al. Reduced glucose metabolism in the frontal cortex and basal ganglia of multiple sclerosis patients with fatigue: a $18 \mathrm{~F}$-fluorodeoxyglucose positron emission tomography study. Neurology 1997;48(6):1566-1571.

186. Freeman L, Garcia-Lorenzo D, Bottin L, et al. The neuronal component of gray matter damage in multiple sclerosis: A [(11) C]flumazenil positron emission tomography study. Ann Neurol 2015;78(4):554-567.

187. Kooi EJ, Prins M, Bajic N, et al. Cholinergic imbalance in the multiple sclerosis hippocampus. Acta Neuropathol 2011;122(3): 313-322. 
188. de Paula Faria D, de Vries EF, Sijbesma JW, Buchpiguel CA, Dierckx RA, Copray SC. PET imaging of glucose metabolism, neuroinflammation and demyelination in the lysolecithin rat model for multiple sclerosis. Mult Scler 2014;20(11):1443-1452.

189. Wu C, Wang C, Popescu DC, et al. A novel PET marker for in vivo quantification of myelination. Bioorg Med Chem 2010;18(24):8592-8599.

190. de Paula Faria D, de Vries EF, Sijbesma JW, Dierckx RA, Buchpiguel CA, Copray S. PET imaging of demyelination and remyelination in the cuprizone mouse model for multiple sclerosis: a comparison between [11C]CIC and [11C]MeDAS. NeuroImage 2014;87:395-402.

191. Liu GJ, Middleton RJ, Hatty CR, et al. The $18 \mathrm{kDa}$ translocator protein, microglia and neuroinflammation. Brain Pathol 2014;24(6):631-653.

192. Svenningsson P, Hall H, Sedvall G, Fredholm BB. Distribution of adenosine receptors in the postmortem human brain: an extended autoradiographic study. Synapse 1997;27(4):322-335.

193. Orr AG, Orr AL, Li XJ, Gross RE, Traynelis SF. Adenosine A(2A) receptor mediates microglial process retraction. Nat Neurosci 2009;12(7):872-878.

194. Vowinckel E, Reutens D, Becher B, et al. PK11195 binding to the peripheral benzodiazepine receptor as a marker of microglia activation in multiple sclerosis and experimental autoimmune encephalomyelitis. J Neurosci Res 1997;50(2):345-353.

195. Banati RB, Newcombe J, Gunn RN, et al. The peripheral benzodiazepine binding site in the brain in multiple sclerosis: quantitative in vivo imaging of microglia as a measure of disease activity. Brain 2000;123:2321-2337.

196. Datta G, Violante IR, Scott G, et al. Translocator positronemission tomography and magnetic resonance spectroscopic imaging of brain glial cell activation in multiple sclerosis. Mult Scler 2016 Nov 1.

197. Okada M, Nakao R, Momosaki S, et al. Improvement of brain uptake for in vivo PET imaging of astrocytic oxidative metabolism using benzyl [1-(11)C]acetate. Appl Radiat Isot 2013;78:102-107.

198. Ponde DE, Dence CS, Oyama N, et al. 18F-fluoroacetate: a potential acetate analog for prostate tumor imaging-in vivo evaluation of 18F-fluoroacetate versus 11C-acetate. J Nucl Med 2007;48(3):420-428.

199. Martin A, Vazquez-Villoldo N, Gomez-Vallejo V, et al. In vivo imaging of system xc- as a novel approach to monitor multiple sclerosis. Eur J Nucl Med Mol Imaging 2016;43(6):1124-1138.

200. Buck D, Forschler A, Lapa C, et al. 18F-FDG PET detects inflammatory infiltrates in spinal cord experimental autoimmune encephalomyelitis lesions. J Nucl Med 2012;53(8):1269-1276.

201. Derache N, Grassiot B, Mezenge F, et al. Fatigue is associated with metabolic and density alterations of cortical and deep gray matter in Relapsing-remitting-multiple sclerosis patients at the earlier stage of the disease: a PET/MR study. Mult Scler Relat Disord 2013;2(4):362-369.

202. Wang $\mathrm{Y}, \mathrm{Wu} \mathrm{C}$, Caprariello $\mathrm{AV}$, et al. In vivo quantification of myelin changes in the vertebrate nervous system. J Neurosci 2009;29(46): 14663-14669.

203. Liu H, Jin H, Yue X, et al. PET imaging study of S1PR1 expression in a rat model of multiple sclerosis. Mol Imaging Biol 2016;18(5):724-732.

204. Moore GR, Leung E, MacKay AL, et al. A pathology-MRI study of the short-T2 component in formalin-fixed multiple sclerosis brain. Neurology 2000;55(10):1506-1510.

205. MacKay A, Whittall K, Adler J, Li D, Paty D, Graeb D. In vivo visualization of myelin water in brain by magnetic resonance. Magn Reson Med 1994;31(6):673-677.

206. Laule C, Leung E, Lis DK, et al. Myelin water imaging in multiple sclerosis: quantitative correlations with histopathology. Mult Scler 2006;12(6):747-753.
207. Moore GR, Laule C, Mackay A, et al. Dirty-appearing white matter in multiple sclerosis: preliminary observations of myelin phospholipid and axonal loss. J Neurol 2008;255(11):1802-1811.

208. Faizy TD, Thaler C, Kumar D, et al. Heterogeneity of multiple sclerosis lesions in multislice myelin water imaging. PLOS ONE 2016;11(3):e0151496.

209. Nguyen TD, Deh K, Monohan E, et al. Feasibility and reproducibility of whole brain myelin water mapping in 4 minutes using fast acquisition with spiral trajectory and adiabatic T2prep (FASTT2) at 3T. Magn Reson Med 2016;76(2):456-465.

210. Kolind S, Matthews L, Johansen-Berg H, et al. Myelin water imaging reflects clinical variability in multiple sclerosis. NeuroImage 2012;60(1):263-270.

211. Oh SH, Bilello M, Schindler M, Markowitz CE, Detre JA, Lee J. Direct visualization of short transverse relaxation time component (ViSTa). NeuroImage 2013;83:485-492.

212. Laule C, Vavasour IM, Moore GR, et al. Water content and myelin water fraction in multiple sclerosis. AT2 relaxation study. J Neurol 2004;251(3):284-293.

213. Kolind S, Seddigh A, Combes A, et al. Brain and cord myelin water imaging: a progressive multiple sclerosis biomarker. NeuroImage Clin 2015;9:574-580.

214. Vargas WS, Monohan E, Pandya S, et al. Measuring longitudinal myelin water fraction in new multiple sclerosis lesions. NeuroImage Clin 2015;9:369-375.

215. Stikov N, Campbell JS, Stroh T, et al. In vivo histology of the myelin g-ratio with magnetic resonance imaging. NeuroImage 2015;118:397-405.

216. Stikov N, Campbell JS, Stroh T, et al. Quantitative analysis of the myelin g-ratio from electron microscopy images of the macaque corpus callosum. Data Brief 2015;4:368-373.

217. Filippi M, Rocca MA, Ciccarelli O, et al. MRI criteria for the diagnosis of multiple sclerosis: MAGNIMS consensus guidelines. Lancet Neurol 2016;15(3):292-303.

218. Okuda DT, Mowry EM, Cree BA, et al. Asymptomatic spinal cord lesions predict disease progression in radiologically isolated syndrome. Neurology 2011;76(8):686-692.

219. Patrucco L, Rojas JI, Cristiano E. Assessing the value of spinal cord lesions in predicting development of multiple sclerosis in patients with clinically isolated syndromes. J Neurol 2012;259(7):1317-1320.

220. Wheeler-Kingshott CA, Stroman PW, Schwab JM, et al. The current state-of-the-art of spinal cord imaging: applications. NeuroImage 2014;84:1082-1093.

221. Riederer I, Karampinos DC, Settles M, et al. Double inversion recovery sequence of the cervical spinal cord in multiple sclerosis and related inflammatory diseases. AJNR Am J Neuroradiol 2015;36(1):219-225

222. Nair G, Absinta M, Reich DS. Optimized T1-MPRAGE sequence for better visualization of spinal cord multiple sclerosis lesions at 3T. AJNR Am J Neuroradiol 2013;34(11):2215-2222.

223. Chong AL, Chandra RV, Chuah KC, Roberts EL, Stuckey SL. Proton density MRI increases detection of cervical spinal cord multiple sclerosis lesions compared with T2-weighted fast spinecho. AJNR Am J Neuroradiol 2016;37(1):180-184.

224. Weier K, Mazraeh J, Naegelin Y, et al. Biplanar MRI for the assessment of the spinal cord in multiple sclerosis. Mult Scler 2012;18(11):1560-1569.

225. Philpott C, Brotchie P. Comparison of MRI sequences for evaluation of multiple sclerosis of the cervical spinal cord at $3 \mathrm{~T}$. Eur J Radiol 2011;80(3):780-785.

226. Breckwoldt MO, Gradl J, Hahnel S, et al. Increasing the sensitivity of MRI for the detection of multiple sclerosis lesions by long axial coverage of the spinal cord: a prospective study in 119 patients. J Neurol 2017;264(2):341-349. 
227. Bot JC, Barkhof F, Polman CH, et al. Spinal cord abnormalities in recently diagnosed MS patients: added value of spinal MRI examination. Neurology 2004;62(2):226-233.

228. Brex PA, Leary SM, O'Riordan JI, et al. Measurement of spinal cord area in clinically isolated syndromes suggestive of multiple sclerosis. J Neurol Neurosurg Psychiatry 2001;70(4):544-547.

229. Brownlee WJ, Altmann DR, Alves Da Mota P, et al. Association of asymptomatic spinal cord lesions and atrophy with disability 5 years after a clinically isolated syndrome. Mult Scler 2017;23(5): 665-674.

230. Nijeholt GJ, Bergers E, Kamphorst W, et al. Post-mortem highresolution MRI of the spinal cord in multiple sclerosis: a correlative study with conventional MRI, histopathology and clinical phenotype. Brain 2001;124(Pt 1):154-166.

231. Kearney H, Altmann DR, Samson RS, et al. Cervical cord lesion load is associated with disability independently from atrophy in MS. Neurology 2015;84(4):367-373.

232. Lukas C, Knol DL, Sombekke MH, et al. Cervical spinal cord volume loss is related to clinical disability progression in multiple sclerosis. J Neurol Neurosurg Psychiatry 2015;86(4):410-418.

233. Liptak Z, Berger AM, Sampat MP, et al. Medulla oblongata volume: a biomarker of spinal cord damage and disability in multiple sclerosis. AJNR Am J Neuroradiol 2008;29(8):1465-1470.

234. Bernitsas E, Bao F, Seraji-Bozorgzad N, et al. Spinal cord atrophy in multiple sclerosis and relationship with disability across clinical phenotypes. Mult Scler Relat Disord 2015;4(1):47-51.

235. Gilmore CP, Geurts JJ, Evangelou N, et al. Spinal cord grey matter lesions in multiple sclerosis detected by post-mortem high field MR imaging. Mult Scler 2009;15(2):180-188.

236. Schlaeger R, Papinutto N, Panara V, et al. Spinal cord gray matter atrophy correlates with multiple sclerosis disability. Ann Neurol 2014;76(4):568-580.

237. Schlaeger R, Papinutto N, Zhu AH, et al. Association between thoracic spinal cord gray matter atrophy and disability in multiple sclerosis. JAMA Neurol 2015;72(8):897-904.

238. Kearney H, Miszkiel KA, Yiannakas MC, Altmann DR, Ciccarelli $\mathrm{O}$, Miller DH. Grey matter involvement by focal cervical spinal cord lesions is associated with progressive multiple sclerosis. Mult Scler 2016;22(7):910-920.

239. Hua LH, Donlon SL, Sobhanian MJ, Portner SM, Okuda DT. Thoracic spinal cord lesions are influenced by the degree of cervical spine involvement in multiple sclerosis. Spinal Cord 2015;53(7):520-525.

240. Qiu W, Raven S, James I, et al. Spinal cord involvement in multiple sclerosis: a correlative MRI and high-resolution HLA-DRB1 genotyping study. J Neurol Sci 2011;300(1-2):114-119.

241. Akkad DA, Bellenberg B, Esser S, et al. Multiple sclerosis risk loci correlate with cervical cord atrophy and may explain the course of disability. Neurogenetics 2015;16(3):161-168.

242. Valsasina P, Rocca MA, Horsfield MA, Copetti M, Filippi M. A longitudinal MRI study of cervical cord atrophy in multiple sclerosis. J Neurol 2015;262(7):1622-1628.

243. Lin X, Tench CR, Turner B, Blumhardt LD, Constantinescu CS. Spinal cord atrophy and disability in multiple sclerosis over four years: application of a reproducible automated technique in monitoring disease progression in a cohort of the interferon beta-1a (Rebif) treatment trial. J Neurol Neurosurg Psychiatry 2003;74(8):1090-1094.

244. Shipova EG, Spirin NN, Kasatkin DS, Shumakov EI, Stepanov IO. State of the cervical section of the spinal cord in patients with remitting multiple sclerosis during immunomodulatory treatment. Neurosci Behav Physiol 2009;39(1):47-51.

245. Singhal T, Tauhid S, Hurwitz S, Neema M, Bakshi R. The effect of glatiramer acetate on spinal cord volume in relapsing-remitting multiple sclerosis. J Neuroimaging 2017;27(1):33-36.
246. Martin AR, Aleksanderek I, Cohen-Adad J, et al. Translating stateof-the-art spinal cord MRI techniques to clinical use: a systematic review of clinical studies utilizing DTI, MT, MWF, MRS, and fMRI. NeuroImage Clin 2016;10:192-238.

247. Oh J, Zackowski K, Chen M, et al. Multiparametric MRI correlates of sensorimotor function in the spinal cord in multiple sclerosis. Mult Scler 2013;19(4):427-435.

248. Zollinger LV, Kim TH, Hill K, Jeong EK, Rose JW. Using diffusion tensor imaging and immunofluorescent assay to evaluate the pathology of multiple sclerosis. J Magn Reson Imaging 2011;33(3):557-564

249. Theaudin M, Saliou G, Ducot B, et al. Short-term evolution of spinal cord damage in multiple sclerosis: a diffusion tensor MRI study. Neuroradiol 2012;54(10):1171-1178.

250. Oh J, Sotirchos ES, Saidha S, et al. Relationships between quantitative spinal cord MRI and retinal layers in multiple sclerosis. Neurology 2015;84(7):720-728.

251. Hesseltine SM, Law M, Babb J, et al. Diffusion tensor imaging in multiple sclerosis: assessment of regional differences in the axial plane within normal-appearing cervical spinal cord. AJNR Am J Neuroradiol 2006;27(6):1189-1193.

252. Benedetti B, Rocca MA, Rovaris M, et al. A diffusion tensor MRI study of cervical cord damage in benign and secondary progressive multiple sclerosis patients. J Neurol Neurosurg Psychiatry 2010;81(1):26-30.

253. Kearney H, Schneider T, Yiannakas MC, et al. Spinal cord grey matter abnormalities are associated with secondary progression and physical disability in multiple sclerosis. J Neurol Neurosurg Psychiatry 2015;86(6):608-614.

254. Minty EP, Bjarnason TA, Laule C, MacKay AL. Myelin water measurement in the spinal cord. Magn Reson Med 2009;61(4): 883-892.

255. Laule C, Yung A, Pavolva V, et al. High-resolution myelin water imaging in post-mortem multiple sclerosis spinal cord: A case report. Mult Scler 2016;22(11):1485-1489.

256. Laule C, Vavasour IM, Zhao Y, et al. Two-year study of cervical cord volume and myelin water in primary progressive multiple sclerosis. Mult Scler 2010;16(6):670-677.

257. Henning A, Schar M, Kollias SS, Boesiger P, Dydak U. Quantitative magnetic resonance spectroscopy in the entire human cervical spinal cord and beyond at 3T. Magn Reson Med 2008;59(6):1250-1258.

258. Marliani AF, Clementi V, Albini Riccioli L, et al. Quantitative cervical spinal cord 3T proton MR spectroscopy in multiple sclerosis. AJNR Am J Neuroradiol 2010;31(1):180-184.

259. Ciccarelli O, Wheeler-Kingshott CA, McLean MA, et al. Spinal cord spectroscopy and diffusion-based tractography to assess acute disability in multiple sclerosis. Brain 2007;130(Pt 8):22202231.

260. Smith AK, Dortch RD, Dethrage LM, Smith SA. Rapid, highresolution quantitative magnetization transfer MRI of the human spinal cord. NeuroImage 2014;95:106-116.

261. Zackowski KM, Smith SA, Reich DS, et al. Sensorimotor dysfunction in multiple sclerosis and column-specific magnetization transfer-imaging abnormalities in the spinal cord. Brain 2009;132(Pt 5):1200-1209.

262. Agosta F, Pagani E, Caputo D, Filippi M. Associations between cervical cord gray matter damage and disability in patients with multiple sclerosis. Arch Neurol 2007;64(9):1302-1305.

263. Rovaris M, Judica E, Sastre-Garriga J, et al. Large-scale, multicentre, quantitative MRI study of brain and cord damage in primary progressive multiple sclerosis. Mult Scler 2008;14(4): 455-464.

264. Kearney H, Yiannakas MC, Samson RS, Wheeler-Kingshott CA, Ciccarelli O, Miller DH. Investigation of magnetization transfer 
ratio-derived pial and subpial abnormalities in the multiple sclerosis spinal cord. Brain 2014;137(Pt 9):2456-2468.

265. Rocca MA, Absinta M, Valsasina P, et al. Abnormal cervical cord function contributes to fatigue in multiple sclerosis. Mult Scler 2012;18(11):1552-1559.

266. Valsasina P, Agosta F, Absinta M, Sala S, Caputo D, Filippi M. Cervical cord functional MRI changes in relapse-onset MS patients. J Neurol Neurosurg Psychiatry 2010;81(4):405-408.

267. Magliozzi R, Howell OW, Reeves C, et al. A gradient of neuronal loss and meningeal inflammation in multiple sclerosis. Ann Neurol 2010;68(4):477-493.

268. Zivadinov R, Ramasamy DP, Vaneckova M, et al. Leptomeningeal contrast enhancement is associated with progression of cortical atrophy in MS: a retrospective, pilot, observational longitudinal study. Mult Scler 2016 Nov 1.

269. Absinta M, Vuolo L, Rao A, et al. Gadolinium-based MRI characterization of leptomeningeal inflammation in multiple sclerosis. Neurology 2015;85(1):18-28.

270. Absinta M, Cortese IC, Vuolo L, et al. Leptomeningeal gadolinium enhancement across the spectrum of chronic neuroinflammatory diseases. Neurology 2017;88:1439-1444.

271. Sastre-Garriga J. Leptomeningeal enhancement in Susac's syndrome and multiple sclerosis: Time to expect the unexpected? Mult Scler 2016;22(7):975-976.

272. Xia Z, Steele SU, Bakshi A, et al. Assessment of early evidence of multiple sclerosis in a prospective study of asymptomatic highrisk family members. JAMA Neurol 2017;74:293-300.

273. Connor JR, Menzies SL. Cellular management of iron in the brain. J Neurol Sci 1995;134(Suppl.):33-44.

274. Hametner S, Wimmer I, Haider L, Pfeifenbring S, Bruck W, Lassmann $\mathrm{H}$. Iron and neurodegeneration in the multiple sclerosis brain. Ann Neurol 2013;74(6):848-861

275. Zhang X, Haaf M, Todorich B, et al. Cytokine toxicity to oligodendrocyte precursors is mediated by iron. Glia 2005;52(3):199208.

276. Mehta V, Pei W, Yang G, et al. Iron is a sensitive biomarker for inflammation in multiple sclerosis lesions. PLOS ONE 2013;8(3): e57573.

277. Dal-Bianco A, Grabner G, Kronnerwetter C, et al. Slow expansion of multiple sclerosis iron rim lesions: pathology and $7 \mathrm{~T}$ magnetic resonance imaging. Acta Neuropathol 2017;133(1):25-42.

278. Yao B, Ikonomidou VN, Cantor FK, Ohayon JM, Duyn J, Bagnato F. Heterogeneity of multiple sclerosis white matter lesions detected with $\mathrm{T} 2 *$-weighted imaging at 7.0 Tesla. J Neuroimaging 2015;25(5):799-806.

279. Absinta M, Sati P, Schindler M, et al. Persistent 7-tesla phase rim predicts poor outcome in new multiple sclerosis patient lesions. J Clin Invest 2016;126(7):2597-2609.

280. Al-Radaideh AM, Wharton SJ, Lim SY, et al. Increased iron accumulation occurs in the earliest stages of demyelinating disease: an ultra-high field susceptibility mapping study in clinically isolated syndrome. Mult Scler 2013;19(7):896-903.

281. Habib CA, Liu M, Bawany N, et al. Assessing abnormal iron content in the deep gray matter of patients with multiple sclerosis versus healthy controls. AJNR Am J Neuroradiol 2012;33(2):252258

282. Quinn MP, Gati JS, Klassen ML, Lee DH, Kremenchutzky M, Menon RS. Increased deep gray matter iron is present in clinically isolated syndromes. Mult Scler Relat Disord 2014;3(2):194-202.

283. Bergsland N, Tavazzi E, Lagana MM, et al. White matter tract injury is associated with deep gray matter iron deposition in multiple sclerosis. J Neuroimaging 2017;27(1):107-113.

284. Brass SD, Benedict RH, Weinstock-Guttman B, Munschauer F, Bakshi R. Cognitive impairment is associated with subcortical magnetic resonance imaging grey matter $\mathrm{T} 2$ hypointensity in multiple sclerosis. Mult Scler 2006;12(4):437-444.
285. Modica CM, Zivadinov R, Dwyer MG, Bergsland N, Weeks AR, Benedict RH. Iron and volume in the deep gray matter: association with cognitive impairment in multiple sclerosis. AJNR Am J Neuroradiol 2015;36(1):57-62.

286. Paling D, Tozer D, Wheeler-Kingshott C, Kapoor R, Miller DH, Golay X. Reduced R2' in multiple sclerosis normal appearing white matter and lesions may reflect decreased myelin and iron content. J Neurol Neurosurg Psychiatry 2012;83(8):785-792.

287. Trattnig S, Springer E, Bogner W, et al. Key clinical benefits of neuroimaging at 7T. NeuroImage 2016 Nov 13 [Epub ahead of print].

288. Tjoa CW, Benedict RH, Weinstock-Guttman B, Fabiano AJ, Bakshi R. MRI T2 hypointensity of the dentate nucleus is related to ambulatory impairment in multiple sclerosis. J Neurol Sci 2005;234(1-2):17-24.

289. Cronin MJ, Wharton S, Al-Radaideh A, et al. A comparison of phase imaging and quantitative susceptibility mapping in the imaging of multiple sclerosis lesions at ultrahigh field. MAGMA 2016;29(3):543-557.

290. Bagnato F, Hametner S, Yao B, et al. Tracking iron in multiple sclerosis: a combined imaging and histopathological study at 7 Tesla. Brain 2011;134(Pt 12):3602-3615.

291. Pitt D, Boster A, Pei W, et al. Imaging cortical lesions in multiple sclerosis with ultra-high-field magnetic resonance imaging. Arch Neurol 2010;67(7):812-818.

292. Hammond KE, Metcalf M, Carvajal L, et al. Quantitative in vivo magnetic resonance imaging of multiple sclerosis at 7 Tesla with sensitivity to iron. Ann Neurol 2008;64(6):707-713.

293. Absinta M, Sati P, Gaitan MI, et al. Seven-tesla phase imaging of acute multiple sclerosis lesions: a new window into the inflammatory process. Ann Neurol 2013;74(5):669-678.

294. Ge Y, Jensen JH, Lu H, et al. Quantitative assessment of iron accumulation in the deep gray matter of multiple sclerosis by magnetic field correlation imaging. AJNR Am J Neuroradiol 2007;28(9):1639-1644.

295. Kilsdonk ID, Wattjes MP, Lopez-Soriano A, et al. Improved differentiation between MS and vascular brain lesions using FLAIR* at 7 Tesla. Eur Radiol 2014;24(4):841-849.

296. Chen X, Zeng C, Luo T, et al. Iron deposition of the deep grey matter in patients with multiple sclerosis and neuromyelitis optica: a control quantitative study by 3D-enhanced susceptibilityweighted angiography (ESWAN). Eur J Radiol 2012;81(4):e633e639.

297. Sheth VR, Fan S, He Q, et al. Inversion recovery ultrashort echo time magnetic resonance imaging: a method for simultaneous direct detection of myelin and high signal demonstration of iron deposition in the brain - a feasibility study. Magn Reson Imaging 2017;38:87-94.

298. Kirschbaum K, Sonner JK, Zeller MW, et al. In vivo nanoparticle imaging of innate immune cells can serve as a marker of disease severity in a model of multiple sclerosis. Proc Natl Acad Sci U S A 2016;113(46):13227-13232.

299. Crimi A, Commowick O, Maarouf A, et al. Predictive value of imaging markers at multiple sclerosis disease onset based on gadolinium- and USPIO-enhanced MRI and machine learning. PLOS ONE 2014;9(4):e93024.

300. Maarouf A, Ferre JC, Zaaraoui W, et al. Ultra-small superparamagnetic iron oxide enhancement is associated with higher loss of brain tissue structure in clinically isolated syndrome. Mult Scler 2016;22(8):1032-1039.

301. Wisnieff C, Ramanan S, Olesik J, Gauthier S, Wang Y, Pitt D. Quantitative susceptibility mapping (QSM) of white matter multiple sclerosis lesions: interpreting positive susceptibility and the presence of iron. Magn Reson Med 2015;74(2):564-570.

302. Zhang Y, Gauthier SA, Gupta A, et al. Longitudinal change in magnetic susceptibility of new enhanced multiple sclerosis (MS) 
lesions measured on serial quantitative susceptibility mapping (QSM). J Magn Reson Imaging 2016;44(2):426-432.

303. Chen W, Gauthier SA, Gupta A, et al. Quantitative susceptibility mapping of multiple sclerosis lesions at various ages. Radiology 2014;271(1):183-192..

304. Fujiwara E, Kmech JA, Cobzas D, et al. Cognitive implications of deep gray matter iron in multiple sclerosis. AJNR Am J Neuroradiol 2017;38:942-948.

305. Schmalbrock P, Prakash RS, Schirda B, et al. Basal ganglia iron in patients with multiple sclerosis measured with $7 \mathrm{~T}$ quantitative susceptibility mapping correlates with inhibitory control. AJNR Am J Neuroradiol 2016;37(3):439-446.

306. Chawla S, Kister I, Wuerfel J, et al. Iron and non-iron-related characteristics of multiple sclerosis and neuromyelitis optica lesions at 7T MRI. AJNR Am J Neuroradiol 2016;37(7):1223-1230.

307. Solomon AJ, Schindler MK, Howard DB, et al. "Central vessel sign" on 3T FLAIR* MRI for the differentiation of multiple sclerosis from migraine. Ann Clin Transl Neurol 2016;3(2):82-87.

308. Sati P, Oh J, Constable RT, et al. The central vein sign and its clinical evaluation for the diagnosis of multiple sclerosis: a consensus statement from the North American Imaging in Multiple Sclerosis Cooperative. Nat Rev Neurol 2016;12(12): 714-722.

309. Ma D, Gulani V, Seiberlich N, et al. Magnetic resonance fingerprinting. Nature 2013;495(7440):187-192.

310. Nakamura K, Deshmane A, Guruprakash D, et al. A novel method for quantification of normal appearing brain tissue in multiple sclerosis: magnetic resonance fingerprinting (P4.158). Neurology 2016;86(16 Suppl.).

311. Hamilton JI, Jiang Y, Chen Y, et al. MR fingerprinting for rapid quantification of myocardial T1, T2, and proton spin density. Magn Reson Med 2017;77(4):1446-1458.

\section{Required Author Forms}

Disclosure forms provided by the authors are available with the online version of this article. 